\title{
Distinct Sonic Hedgehog signaling dynamics specify floor plate and ventral neuronal progenitors in the vertebrate neural tube
}

\author{
Vanessa Ribes, ${ }^{1,4}$ Nikolaos Balaskas, ${ }^{1,4}$ Noriaki Sasai, ${ }^{1,4}$ Catarina Cruz, ${ }^{1}$ Eric Dessaud, ${ }^{1}$ Jordi Cayuso, ${ }^{2}$ \\ Samuel Tozer, ${ }^{1}$ Lin Lin Yang, ${ }^{3}$ Ben Novitch, ${ }^{3}$ Elisa Marti, ${ }^{2}$ and James Briscoe ${ }^{1,5}$ \\ ${ }^{1}$ Developmental Neurobiology, Medical Research Council-National Institute for Medical Research, London NW7 1AA, United \\ Kingdom; ${ }^{2}$ Instituto de Biología Molecular de Barcelona, Consejo Superior de Investigaciones Científicas (CSIC), Barcelona \\ 08028, Spain; ${ }^{3}$ Department of Neurobiology, Broad Center of Regenerative Medicine and Stem Cell Research, David Geffen \\ School of Medicine at University of California at Los Angeles, Los Angeles, California 90095, USA
}

The secreted ligand Sonic Hedgehog (Shh) organizes the pattern of cellular differentiation in the ventral neural tube. For the five neuronal subtypes, increasing levels and durations of Shh signaling direct progenitors to progressively more ventral identities. Here we demonstrate that this mode of action is not applicable to the generation of the most ventral cell type, the nonneuronal floor plate (FP). In chick and mouse embryos, FP specification involves a biphasic response to Shh signaling that controls the dynamic expression of key transcription factors. During gastrulation and early somitogenesis, FP induction depends on high levels of Shh signaling. Subsequently, however, prospective FP cells become refractory to Shh signaling, and this is a prerequisite for the elaboration of their identity. This prompts a revision to the model of graded Shh signaling in the neural tube, and provides insight into how the dynamics of morphogen signaling are deployed to extend the patterning capacity of a single ligand. In addition, we provide evidence supporting a common scheme for FP specification by Shh signaling that reconciles mechanisms of FP development in teleosts and amniotes.

[Keywords: Shh signaling; neural tube; floor plate; FoxA2]

Supplemental material is available at http://www.genesdev.org.

Received September 30, 2009; revised version accepted April 7, 2010.

During development, an extraordinary array of differentiated cell types with diverse properties and functions are produced in a spatially and temporally coordinated manner. Considerable progress has been made in elucidating the molecular mechanisms that underlie this process. In broad terms, cell-autonomous determinants specify cell fate by regulating the transcriptional programs of initially uncommitted progenitor populations (Jessell 2000; Davidson et al. 2002). Extrinsic signaling molecules, emanating from specialized organizer regions within developing tissues, control the expression of these cell fate determinants (Jessell 2000). This signaling function, however, is performed by a remarkably small number of secreted molecules that are iteratively deployed during embryonic development. Thus, understanding how cells perceive and interpret these signals to produce the cellular

\footnotetext{
${ }^{4}$ These authors contributed equally to this work.

${ }^{5}$ Corresponding author.

E-MAIL james.briscoe@nimr.mrc.ac.uk; FAX 44-20-8816-2523.

Article is online at http://www.genesdev.org/cgi/doi/10.1101/gad.559910.
}

diversity characteristic of a tissue is a central question in developmental biology.

The vertebrate CNS represents a good model to address this issue. In this tissue, the organized generation of many different cell types initiates the assembly of functional neural circuits (Jessell 2000). In ventral regions of the caudal neural tube, six progenitor domains arrayed along the dorsal ventral (DV) axis give rise to a set of neuronal cell types: V0, V1, V2, and V3 interneurons; motor neurons (MNs); and nonneuronal floor plate (FP) cells (Jessell 2000). The FP, p3, and pMN domains-which generate $\mathrm{FP}$, V3 neurons, and $\mathrm{MNs}$, respectively-are arranged in the most ventral part of the neural tube (Fig. 1A); FP cells are distinguished from the two neural cell types by their wedge-shaped morphology and organizer function (Schoenwolf et al. 1989; Ericson et al. 1996; TessierLavigne and Goodman 1996). Furthermore, the identity and function of each of these three progenitor domains are determined by the expression of a set of transcription factors (Dessaud et al. 2008). The basic helix-loop-helix (bHLH) factor Olig2 is expressed by pMN cells and is 

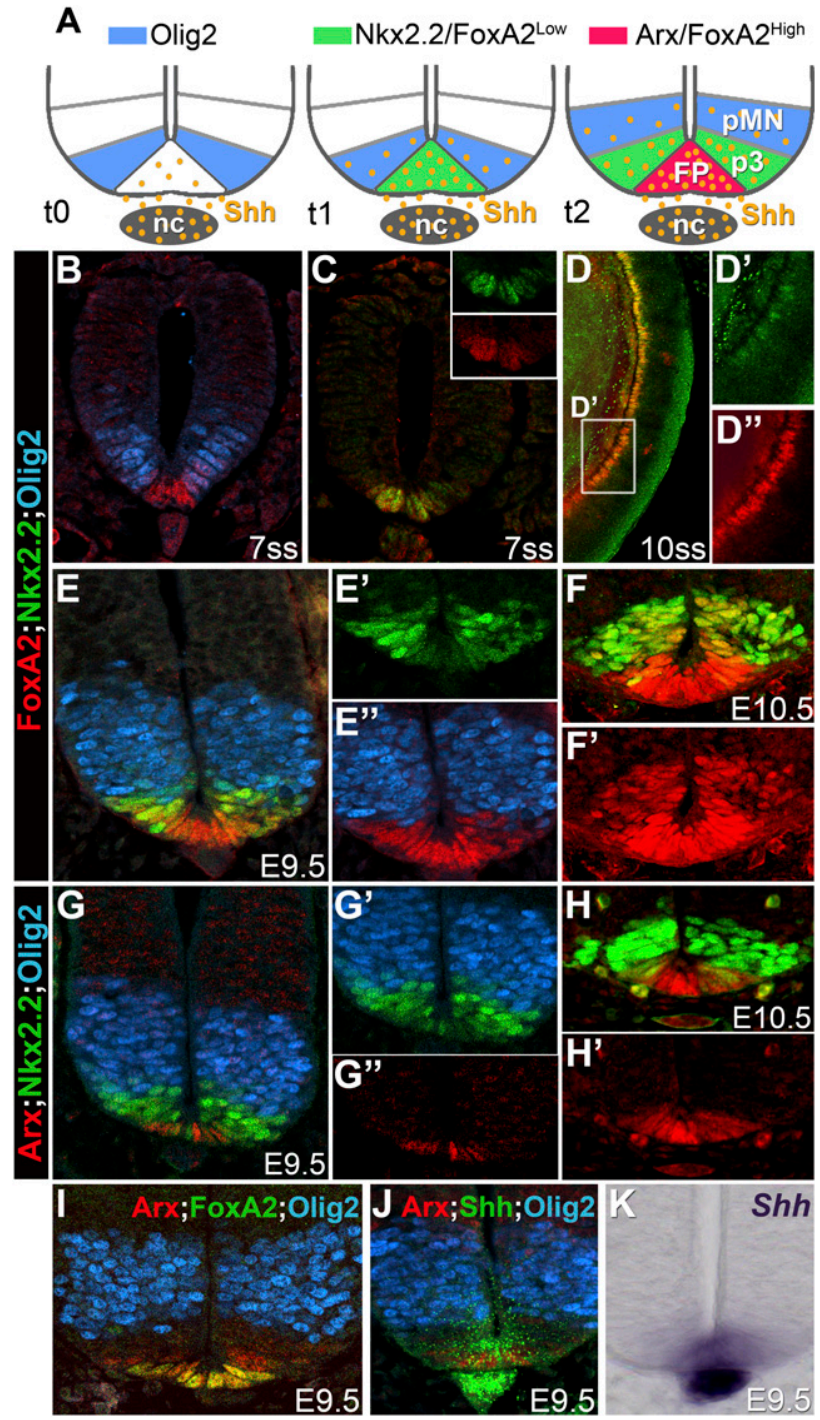

Figure 1. Gene expression profiles within midline cells of mouse neural tube. (A) Schematic depicting the dynamics of gene expression and Shh gradient within the ventral neural tube. (nc) Notochord. $(B-K)$ Expression of FoxA2, Arx, Shh, Nkx2.2, and Olig2 (B- $I)$, and $S h h(K)$ mRNA showing the progressive appearance of FP markers at the midline of the neural tube from $7 \mathrm{ss}$ embryos. $(B-K)$ Transverse sections at brachial levels of the neural tube. $\left(D-D^{\prime \prime}\right)$ Lateral view of a whole embryo. $\left(C-D^{\prime \prime}\right)$ FoxA2 protein is first observed from $7 \mathrm{ss}$ in ventral midline cells that express $\mathrm{Nkx} 2.2$. $\left(D-D^{\prime \prime}\right)$ FoxA2 expression appears more robust than the scattered Nkx2.2 expression at posterior levels of the neural tube. $(B)$ At these stages, FoxA2 expression domain abuts Olig2-expressing cells. $\left(E, E^{\prime \prime}\right)$ From E9.5 onward, the dorsal limit of FoxA2 is no longer adjacent to Olig2-expressing cells. Its expression is stronger at the midline, and weaker in cells that express $\mathrm{Nkx} 2.2 .\left(E-F^{\prime}\right)$ This pattern persists until E10.5. From this stage, additional FP markers, Arx $(G-I)$ and Shh $(J, K)$, appear in cells expressing high levels of FoxA2. $\left(G-H^{\prime}\right)$ Concomitant to the induction of these markers, $\mathrm{Nkx} 2.2$ is no longer seen in the midline; hence, Arx and Shh are barely coexpressed with $\mathrm{Nkx} 2.2$-expressing cells.

required for the generation of MNs, while the homeodomain protein Nkx2.2 is expressed in p3 progenitors and induces V3 neurons (Dessaud et al. 2008). FP cells express the forkhead transcription factor FoxA2, which is sufficient to induce FP identity (Sasaki and Hogan 1994). Notably, however, the requirement for FoxA2 for FP generation has been difficult to assess because mouse embryos lacking FoxA2 fail to gastrulate and die prior to the emergence of FP (Ang and Rossant 1994; Weinstein et al. 1994).

The spatial expression of these transcription factors in the neural tube-and, consequently the location of the pMN, p3, and FP domains-is regulated by the secreted signaling molecule Sonic Hedgehog (Shh) (Dessaud et al. 2008). Initially produced by the node and notochord, lying ventral to neural tissue, and later by cells of the FP, Shh forms a ventral-to-dorsal gradient, the amplitude of which increases with time as more Shh is produced from the notochord and FP (for example, see Chamberlain et al. 2008). The prevailing model for how Shh signaling regulates progenitor patterning suggests that higher concentrations of ligand and longer durations of intracellular signaling induce the expression of increasingly more ventral genes (Dessaud et al. 2008). In support of this, Nkx2.2 is induced by a higher concentration and a longer duration of Shh signaling than Olig2 (Dessaud et al. 2007; Chamberlain et al. 2008). In this view, FP, as the most ventral cell type in the neural tube, should require higher levels and longer durations of Shh signaling than p3 cells. Consistent with this, mice lacking the transmembrane protein Smo or Gli transcription factors, which are involved in the transduction of Shh signal, demonstrated that FP specification requires Shh signaling (Chiang et al. 1996; Matise et al. 1998; Zhang et al. 2001; Bai et al. 2002). In addition, high concentrations of Shh appear to induce FP markers at the expense of MN markers in neural explants (Placzek et al. 1991; Roelink et al. 1995; Ericson et al. 1996). However, the ability of Shh to induce FP markers in neural progenitors seems to be context-dependent. For instance, gainof-function experiments in chicks indicate that $\mathrm{Shh}$ is sufficient to induce MNs and V3 neurons, but not FP cells, in the dorsal part of the neural tube (Placzek et al. 1993; Charrier et al. 2002; Patten and Placzek 2002). In this context, instead of acting as an inductive signal for FP specification, permissive or survival functions have been ascribed to Shh (Charrier et al. 2001). In addition, the requirement for Shh signaling for FP formation does not appear to be conserved in all vertebrates. In particular, blockade of hedgehog signaling in zebrafish has little, if any, effect on the emergence of the FP /Odenthal et al. 2000; Varga et al. 2001). Instead, Nodal signaling has been implicated in FP induction in zebrafish (Hatta et al. 1991; Sampath et al. 1998; Tian et al. 2003). This has led to the idea that different vertebrate species have adopted distinct mechanisms of FP induction, and has raised questions about the function of Shh as a morphogen during FP development.

Here we test whether the Shh morphogen model of neural tube patterning applies to FP development in chicks and mice. We confirm that high levels of Shh signaling are initially necessary for FP specification. However, blockade of Shh signaling after the initiation of somitogenesis inhibits the patterning of neural progenitors in the ventral neural tube, but not FP specification. Moreover, following 
initial induction of FP specification, Shh signaling is attenuated in presumptive FP cells. Maintaining Shh signaling at this time converts FP cells to ventral neural progenitors, demonstrating that the down-regulation of signaling is a prerequisite for the elaboration of FP identity. Thus, the specification of the FP and other ventral neuronal progenitors depends on distinct timing and duration of Shh signaling. Consistent with this, we demonstrate that presumptive FP cells display a dynamic transcriptional code that distinguishes FP precursors from ventral neural progenitors. We provide evidence that FoxA2 is required for FP specification and the inhibition of $\mathrm{p} 3$ fate. Together, these data prompt a revision to the model of Shh-dependent patterning of the neural tube, and offer new insight into how the dynamics of morphogen signaling extend the patterning capacity of a single signal. Furthermore, we provide evidence that the timing of Shh signaling during FP specification is conserved between teleosts and amniotes, suggesting it represents a general feature of vertebrate FP development.

\section{Results}

\section{A dynamic transcriptional code identifies FP progenitors}

We first assessed the dynamics of gene expression within the midline of the forming neural tube. The transcription factor FoxA2 is commonly used as a marker of FP cells (Ericson et al. 1996; Patten and Placzek 2002; Norton et al. 2005). FoxA2 is expressed in the ventral layer of the node and in the notochord from embryonic day 7.5 (E7.5) in mice, where it orchestrates gastrulation (Ang and Rossant 1994; Weinstein et al. 1994). It is then induced in the ventral midline of the anterior neural plate from the 6-somite stage (ss), slightly later than the induction of Olig2 and prior to Nkx2.2, markers of the pMN and p3 progenitor domains, respectively (Fig. 1B-D"; data not shown). At these stages, the dorsal extent of FoxA2 approximates the ventral boundary of Olig2 (Fig. 1B). By $12-14 \mathrm{ss}, \mathrm{Nkx} 2.2$ is induced in the midline of the neural tube in FoxA2-expressing cells (Supplemental Fig. S1A,B; Jeong and McMahon 2005; data not shown). Subsequently, as development proceeds, Nkx2.2 expression is extinguished from midline cells and becomes restricted to the progenitors of the V3 neurons (Fig. 1E-E"; Supplemental Fig. S1C-F). Low levels of FoxA2 expression persist in Nkx2.2-expressing cells (Fig. 1E-F'; Supplemental Fig. S1C-E, arrowheads). In contrast, midline cells devoid of Nkx2.2 expression display high levels of FoxA2 (Fig. 1E-F'; Supplemental Fig. S1A-F); at this stage, we termed these FP cells.

The presence of FoxA2 in the p3 domain prompted us to examine whether we could identify other markers that exclusively mark FP cells. The transcription factor Arx was a good candidate, as it has been detected in the FP of mouse embryos (Miura et al. 1997) and is restricted to the medial FP in zebrafish (Norton et al. 2005). Its expression was not detected before E9.5 (data not shown). From E9.5, Arx was limited to midline cells of the neural tube that express FoxA2 and are negative for Nkx2.2 (Fig. 1G-I; Supplemental Fig. S1C-F). The induction of Arx corresponded to the time at which strong expression of Shh could be detected in the FP (Fig. 1J,K). Together, these data suggest that FP specification is progressive: First, midline cells, which constitute the presumptive FP, express a set of markers that are common to $\mathrm{p} 3$ progenitors, including FoxA2 and Nkx2.2. Then, Nkx2.2 is downregulated, and late FP markers, including Shh and Arx, are induced (Supplemental Fig. S1K).

The expression pattern of Olig2 suggests that the cells that become FP rarely, if ever, express Olig2. Consistent with this, lineage analysis of cells that had expressed Olig2 revealed that, although p3 progenitors descended from Olig2-expressing cells, FP cells only very rarely had an Olig2 pedigree (Supplemental Fig. S1G-J'; Dessaud et al. 2007). This indicates that the history of Olig2 expression can be used to discriminate cells destined to be FP cells from $\mathrm{p} 3$ progenitors, both of which express Nkx2.2 during their development. Together, therefore, these data provide evidence that a dynamic transcriptional code distinguishes ventral progenitor populations, and that the FP lineage segregates from neural progenitors prior to Olig2 induction (Supplemental Fig. S1K).

\section{Transient high levels of Shh signaling are sufficient to induce FP cells}

The progression from a $\mathrm{p} 3$ to FP gene expression profile in midline cells would be consistent with higher levels and/ or longer durations of Shh signaling regulating this switch (Dessaud et al. 2008). To better understand the dynamics of Shh signaling associated with the emergence of FP identity, we took advantage of chick ex vivo experiments (Fig. 2A). Naïve explants taken from the intermediate region ([i] explants) of the neural plate induce FoxA2 in response to high concentrations of Shh, while lower concentrations of Shh result in MN generation (Ericson et al. 1996). In order to distinguish p3 and FP fates, we assayed the expression of Nkx2.2 and Arx, specific markers of p3 and FP, respectively. Exposure to $1 \mathrm{nM}$ Shh for $48 \mathrm{~h}$ predominantly induced Nkx2.2, and few, if any, Arxexpressing cells were detected (Fig. 2B,F). In contrast, explants cultured in the presence of $\geq 4 \mathrm{nM}$ Shh for $48 \mathrm{~h}$ contained large numbers of Arx-expressing cells (Fig. 2C,F; data not shown), and the expression of Nkx2.2 was markedly reduced compared with cells exposed to $1 \mathrm{nM} \mathrm{Shh}$ (Fig. $2 \mathrm{C}, \mathrm{F})$. These data indicate that the induction of FP identity requires high concentrations of Shh, while lower concentrations are sufficient to induce p3 identity.

To investigate the timing of FP induction, we next assayed the expression of Arx and Nkx2.2 in [i] explants exposed to 4-8 nM Shh for $24 \mathrm{~h}$. In these conditions, few cells expressed Arx, and most cells expressed Nkx2.2 (Fig. $2 \mathrm{~F}$; data not shown). The expression profiles of $N k x 2.2$ and Arx mRNA were consistent with this analysis (Fig. 2G): In the presence of $4 \mathrm{nM}$ Shh, Nkx2.2 was induced within $12 \mathrm{~h}$, while $1 \mathrm{nM} \mathrm{Shh}$ resulted in a delayed induction of $N k x 2.2$. The levels of $N k x 2.2$ expression in [i] explants exposed to $4 \mathrm{nM}$ decreased markedly from $24 \mathrm{~h}$, 

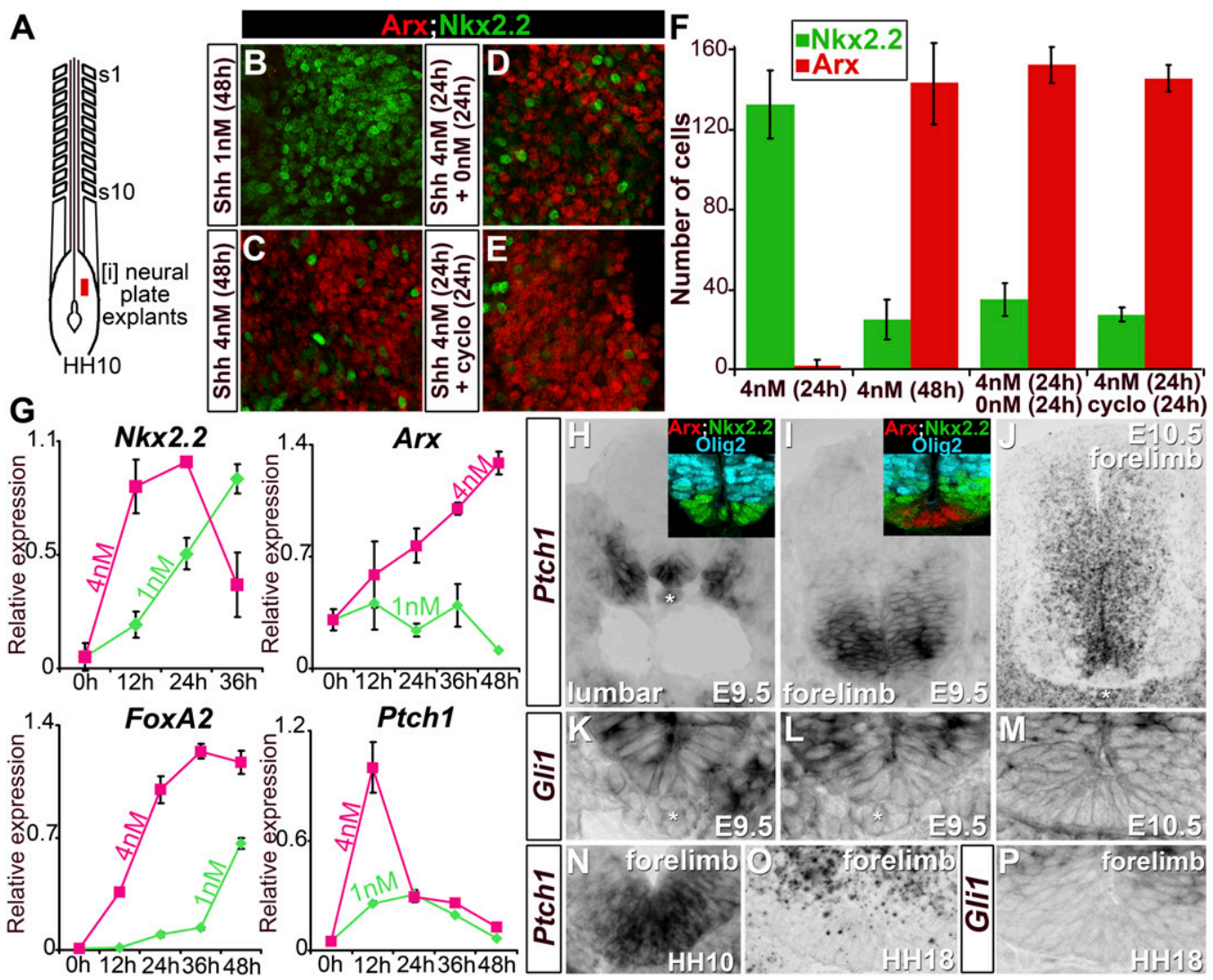

Figure 2. Induction of FP markers by transient high levels of Shh signaling. (A) Schematic of HH10 chick embryos indicating the position of [i] neural plate explants. $(B-E)$ Expression of Arx and Nkx2.2 in [i] neural plate explants after $48 \mathrm{~h}$ of culture. Cells in explants treated with $1 \mathrm{nM}$ Shh exclusively express $\mathrm{Nkx} 2.2(B)$, while $4 \mathrm{nM}$ Shh promotes FP fate, identified by Arx expression $(C)$. In explants first exposed for $24 \mathrm{~h}$ to $4 \mathrm{nM}$ Shh and then placed in a media either devoid of Shh $(D)$ or containing $500 \mathrm{nM}$ cyclopamine (cyclo) (E), FP induction is retained. (F) Quantification of cells expressing Arx and Nkx2.2 in [i] neural plate explants after 24 or $48 \mathrm{~h}$ of culture $(n \geq 4$ explants, number of cells per unit \pm SD). (G) Temporal dynamics of Nkx2.2, Arx, FoxA2, and Ptch1 expression relative to Actin transcripts and normalized between sets of experiments assayed by quantitative PCR in [i] neural plate explants treated with $1 \mathrm{nM}$ (pale green) or $4 \mathrm{nM}$ (pink) Shh ( $n \geq 2$ experiments, mean $\pm \mathrm{SD})$. As definitive FP markers are induced, p3 markers and Ptch1 are down-regulated. $(H-P)$ Expression of Ptch1 $(H-I, N-O)$ and Gli1 $(K-M, P)$ in mouse embryos $(H-M)$ and chick embryos $(N-P)$. Insets in $H$ and $I$ indicate Arx, Nkx2.2, and Olig2 expression on sections adjacent to the main panel. Midline cells transiently express high levels of Ptch1 and Gli1. The asterisks indicate the notochord.

concomitant with the induction of Arx. The induction of FoxA2 mirrored that of $N k x 2.2$, but its expression was sustained after $24 \mathrm{~h}$ in explants exposed to $4 \mathrm{nM}$ Shh (Fig. $2 \mathrm{G})$. These data suggest that the induction of FP identity in [i] explants requires high concentrations of Shh and takes between 24 and $48 \mathrm{~h}$.

We next asked what duration of Shh signaling was required for the induction of FP. To address this, we exposed [i] explants to $4 \mathrm{nM}$ Shh for $24 \mathrm{~h}$, then replaced the media with fresh media that either lacked Shh or contained cyclopamine, an antagonist of the intracellular transducer of the signaling pathway, Smo (Cooper et al. 1998; Incardona et al. 1998). Explants were then cultured for an additional $24 \mathrm{~h}$ (Fig. 2D-F). Blockade of Shh signaling at $24 \mathrm{~h}$ did not appear to affect the elaboration of FP identity; the expression profile of Arx and Nkx2.2 was indistinguishable from explants that were continuously cultured in the presence of $4 \mathrm{nM}$ Shh for $48 \mathrm{~h}$ (Fig. 2D-F). Thus the requirement for Shh signaling for the specifica- tion of FP appears to be transient, and does not depend on signaling being sustained beyond $24 \mathrm{~h}$.

We next assayed for the expression profile of Ptch1 as a readout of Shh signaling (Marigo and Tabin 1996; Vokes et al. 2008). In the presence of 1 or $4 \mathrm{nM} \mathrm{Shh,} \mathrm{Ptch1} \mathrm{was}$ rapidly induced, and levels of expression peaked at $12 \mathrm{~h}$ (Fig. 2G). The peak levels of expression were higher in [i] explants exposed to $4 \mathrm{nM}$ than $1 \mathrm{nM}$ Shh, consistent with the requirement for high levels of signaling for FP induction (Fig. 2F). Following the peak, however, the expression levels of the Shh target gene began to decline. Compared with [i] explants exposed to $1 \mathrm{nM}$, in explants treated with $4 \mathrm{nM}$ Shh, the decrease of Ptch1 expression was more rapid and resulted in an $\sim 70 \%$ drop in the levels of expression by $24 \mathrm{~h}(n=4)$. Similarly, the expression of another Shh target gene, Gli1 (Marigo et al. 1996; Lee et al. 1997; Vokes et al. 2008), displayed a higher peak that decreased more rapidly in response to $4 \mathrm{nM}$ compared with $1 \mathrm{nM}$ Shh (Supplemental Fig. S4B). These data 
suggest that cells become progressively refractory to Shh, and support the idea that high but transient signaling is sufficient to induce FP identity.

In vivo, a similar dynamic profile of Shh signaling is associated with the specification of FP cells. In lumbar regions of E9.5 mouse embryos, ventral midline cells expressed FoxA2 and Nkx2.2 (Fig. 2H, inset; data not shown) and high levels of Ptch1 (Fig. 2H). Similarly, high levels of Ptch1 were found within the most ventral regions of Hamburger-Hamilton 10 (HH10) chick neural tubes (Fig. $2 \mathrm{~N})$. This is indicative of presumptive FP cells receiving high levels of Shh signaling. However, at brachial levels of E9.5 mouse embryos, which are developmentally more mature, Arx was expressed, while Nkx2.2 was down-regulated (Fig. 2I, inset), and the levels of Ptch1 expression were noticeably reduced in midline cells (Fig. 2I). In contrast, high levels of Ptch1 were observed in neural progenitors comprising the $\mathrm{p} 3$ domain. A similar expression profile was observed for Gli1 (Fig. 2K,L). By E10.5, Ptch1 and Gli1 expression was markedly decreased in FP cells compared with the levels in the $\mathrm{p} 3$ or pMN along the entire anteriorposterior axis of the neural tube (Fig. 2J,M). Likewise, decreased levels of Ptch1 and Gli1 were apparent in the FP of HH18 chick embryos compared with the p3 domain (Fig. 2O,P). Moreover, in Ptch1 mutant embryos, which display early, ectopic Hh signaling (Supplemental Fig. S4, cf. H,L and F,J; Goodrich et al. 1997), the expression of FP markers was concurrent with a down-regulation of Shh signaling (Supplemental Fig. S4, cf. I,M and G, K; Motoyama et al. 2003).

Together, these data suggest that a transient burst of Shh signaling, generated by high concentrations of Shh, is sufficient to trigger FP specification. Importantly, the appearance of definitive FP markers is correlated with a drop in the levels of Shh signaling. This raises several questions. First, for how long is Shh signaling required for FP specification in vivo? Second, can neural progenitors anywhere within the spinal cord give rise to FP cells when exposed to high concentrations of Shh? Third, is the down-regulation of Shh signaling in FP precursors a prerequisite for the elaboration of FP identity? Finally, what are the molecular cues that relay Shh signaling during FP specification?

\section{Shh signaling is required prior to somitogenesis for FP specification}

To assay the timing of Shh signaling required to specify FP identity in vivo, we cultured whole mouse embryos in the presence of cyclopamine at different time points and analyzed the expression of progenitor domain markers. Embryos exposed to cyclopamine from the headfold stage (E7.75) displayed a very marked decrease in the expression of ventral markers, including Olig2, Nkx2.2, and Arx (Fig. 3, cf. B,D and A,C; Supplemental Fig. S2D-F). Concomitantly, the expression of Pax6, expressed in the dorsal neural tube, expanded toward the midline of the neural tube (Fig. 3B). This phenotype recapitulates the neural tube patterning defects observed in mice lacking Shh or Smo (Chiang et al. 1996; Zhang et al. 2001). Similarly, incubation of embryos with cyclopamine from 3ss, which is prior to the induction of ventral neural progenitor markers, also reduced the expression of pMN and p3 markers (Fig. 3, cf. F,H,L and E,G,K; Supplemental Fig. S2G-I), and resulted in a ventral expansion of Pax6 expression (Fig. 3, cf. F and E). In these embryos, however, expression of Arx, FoxA2, and Shh was detected (Fig. 3, cf. H,J,L and G,I,K; Supplemental Fig. S2G-I), albeit the total number of FP cells was reduced compared with controls. Moreover, treatments performed after $14 \mathrm{ss}$ did not affect the extent of the FP (Fig. 3, cf. J,L and I,K; Supplemental Fig. S2J-L) despite reducing ventral neural progenitors. These data demonstrate that, in mice, Shh signaling is required transiently before 10-12ss for FP specification within the hindbrain and the entire spinal cord.

In chicks, as in mice, Shh signaling is also required for FP development (Incardona et al. 1998). To test whether specification of chick FP cells was also only transiently dependent on Shh signaling, we blocked Shh signaling in vivo in neural cells using a dominant active form of the receptor Ptch1 (Ptc1 ${ }^{\Delta l o o p 2}$ ) (Briscoe et al. 2001). Expression of Ptc1 $1^{\text {Sloop2 }}$ at HH12-a stage at which FoxA2 is strongly expressed in the midline and $\mathrm{Nkx} 2.2$ expression is initiated in the p3 domain (data not shown)-downregulated $\mathrm{Nkx} 2.2$ expression in a cell-autonomous manner (Fig. 3N), but did not affect the expression of Arx and FoxA2 (Fig. 3M-M"). These data indicate that the specification of FP cells in amniotes requires Shh signaling transiently early in development. In contrast, the patterning of the progenitors of ventral neuronal subtypes has a prolonged requirement for Shh signaling.

In contrast to amniotes, previous studies suggested that, in zebrafish, Shh signaling plays a less significant role in inducing FP cells (Supplemental Fig. S3A-F; Odenthal et al. 2000; Albert et al. 2003). In this species, Nodal is the primary signal responsible for FP specification (Hatta et al. 1991; Sampath et al. 1998; Tian et al. 2003). Nevertheless, in zebrafish lacking Nodal signaling, FP cells are induced, but only after somitogenesis, and this induction is dependent on Shh signaling (Odenthal et al. 2000; Albert et al. 2003). This has led to the suggestion that Shh signaling functions to maintain FP identity in zebrafish at post-somitogenesis stages. We challenged this model by using cyclopamine to block Shh signaling at different time points in embryos in which Nodal signaling had been compromised using the Nodal receptor inhibitor SB431542 (Supplemental Fig. S3J-L; Hagos and Dougan 2007). In zebrafish embryos incubated with SB431542 from $30 \%$ epiboly $(4.67$ h post-fertilization [hpf]), shh expression was detected in a few scattered cells of the medial FP at 24 hpf (Supplemental Fig. S3Q), but along the entire length of the spinal cord at $48 \mathrm{hpf}$ (Fig. 3U). Moreover, the expression of foxa2, which marks both the medial FP and Nkx2.2-expressing cells (termed the lateral FP in zebrafish) (Schafer et al. 2007), was unaltered at $48 \mathrm{hpf}$ (Fig. 3, cf. P and O). This is reminiscent of the phenotype of zebrafish mutant for the Nodal receptor (Hatta et al. 1991; Sampath et al. 1998). In contrast, in zebrafish embryos incubated with SB432542 and cylopamine from 30\% epiboly, both lateral and medial FP markers were absent at 24 and 48 hpf (Fig. 3Q,U; Supplemental Fig. S3O,R). 


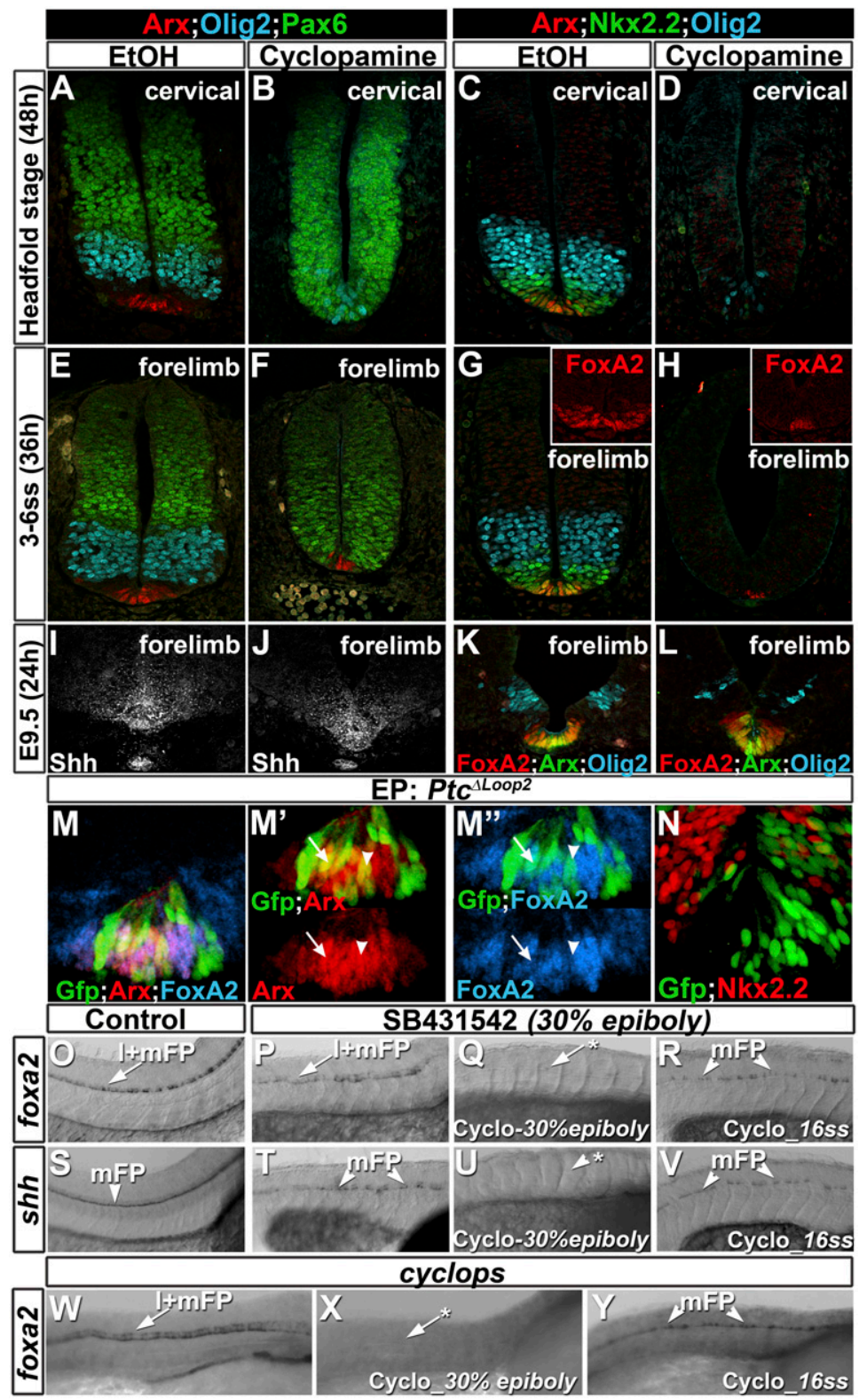

Figure 3. Requirement for Shh signaling prior to somitogenesis for FP specification. $(A-L)$ Arx, FoxA2, Nkx2.2, Olig2, and Pax6 expression at forelimb levels of the neural tube in embryos cultured with vehicle, $\mathrm{EtOH}$ $(A, C, E, I, G, K), 5 \mu \mathrm{M}$ cyclopamine $(B, D, F, H)$, or $10 \mu \mathrm{M}$ cyclopamine $(J, L)$ from the headfold stage $(A-D), 3-5 \mathrm{ss}$ $(E-H)$, and E9.5 $(I-L)$ for 48,36 , and $24 \mathrm{~h}$, respectively. Cyclopamine treatment affected the expression of $\mathrm{p} 3$ and pMN markers in all conditions, but only inhibited the emergence of FP markers if added prior to 3 ss. $(M-N)$ Transfection of $P t c 1^{\Delta l o o p 2}$ in the ventral neural tube of HH12 chick embryos assayed for Arx, FoxA2, and Nkx2.2. Ptc1 $1^{\text {sloop2 }}$ does not affect the expression of FP markers $\left(M, M^{\prime \prime}\right)$, but down-regulates $\mathrm{Nkx} 2.2$ expression $(N) .(O-V)$ Zebrafish embryos assayed for foxa2 and shh expression 48 hpf treated with vehicle, $\mathrm{EtOH}+\mathrm{DMSO}$ $(O, S), 800 \mu \mathrm{M}$ SB431542 alone from $30 \%$ epiboly $(P, T)$, or a combination of $5 \mu \mathrm{M}$ cyclopamine and $800 \mu \mathrm{M}$ SB431542 added at either $30 \%$ epiboly $(Q, U)$ or $16 \mathrm{ss}$ $(R, V) .(O, S)$ In control embryos, shh and foxa2 were expressed within the medial FP (mFP) and the lateral and medial FP $(1+\mathrm{mFP})$, respectively. While in embryos treated with SB431542 alone, both genes are expressed in the spinal cord $(P, T$; foxa2: $n=24$ of 26 ; shh: $n=27$ of 29 ), embryos treated with SB431542 and cyclopamine from $30 \%$ epiboly lack cells expressing these genes $(Q, U$; foxa2: 25 of 33; in eight of 33 a few cells were observed; shh: 23 of 31). The addition of cyclopmaine at 16ss in SB431542-treated embryos does not impair shh or foxa2 expression in the medial FP, but down-regulates foxa2 expression in the lateral FP (foxa2: 34 of 37; in three embryos the expression was weak; shh: 21 of 28; see also Supplemental Fig. S3). (W-Y) Zebrafish cyclops mutant embryos assayed for foxa2 expression at $48 \mathrm{hpf}$ treated with vehicle, EtOH $(W)$, or $5 \mu \mathrm{M}$ cyclopamine added at either $30 \%$ epiboly $(X)$ or 16 ss $(T)$. Embryos treated with cyclopamine from $30 \%$ epiboly lack cells expressing foxa2 $(n=9$ of 9$)$, while those treated from 16ss or with vehicle do express foxa2 $\mid n=$ 8 of 9 and 7 of 7 , respectively). The asterisks indicate absence of expression.
Strikingly, addition of cyclopamine to 16ss embryos $(17$ hpf) that had been incubated with SB431542 from 30\% epiboly did not affect the medial FP expression of shh or foxa2 at $48 \mathrm{hpf}$ (Fig. 3R,V). However, addition of cyclopamine at this stage continued to block expression of foxa2 and $n k x 2.2$ in the lateral FP, consistent with the idea that Shh signaling at $16 \mathrm{ss}$ is required for the development of lateral $\mathrm{FP} / \mathrm{p} 3$ progenitors but not the Shh-expressing medial FP (Supplemental Fig. S3G-I; Odenthal et al. 2000). Similarly, cyclops mutant embryos expressed medial FP markers when treated with cyclopamine from 16ss (Fig. 3Y; Supplemental Fig. S3U), but not when incubated with the drug from 30\% epiboly (Fig. 3X; Supplemental Fig. S3T). Together, these data indicate that Shh signaling in zebrafish, as in amniotes, regulates FP specification during gastrulation and early somitogenesis.
The timing of the competence to respond to Shh restricts the spatial extent of FP identity

Previous studies demonstrated that Shh was not sufficient to drive neural progenitors within the spinal cord toward a FP identity (Charrier et al. 2002; Patten and Placzek 2002). Accordingly, the ectopic expression of an active form of Shh $(S h h N)$ in cervical and thoracic levels of HH11-12 chick embryo neural tubes induced the p3 marker Nkx2.2 and low levels of FoxA2 on both sides of the neural tube. However, Arx expression was unaffected (Fig. 4A-D). In contrast, at more caudal levels of the same embryos, which contain developmentally younger neural cells, widespread induction of Arx was observed (Fig. 4D, inset). This suggested that the distinction between $\mathrm{p} 3$ and FP is a consequence of the time at which cells are exposed 


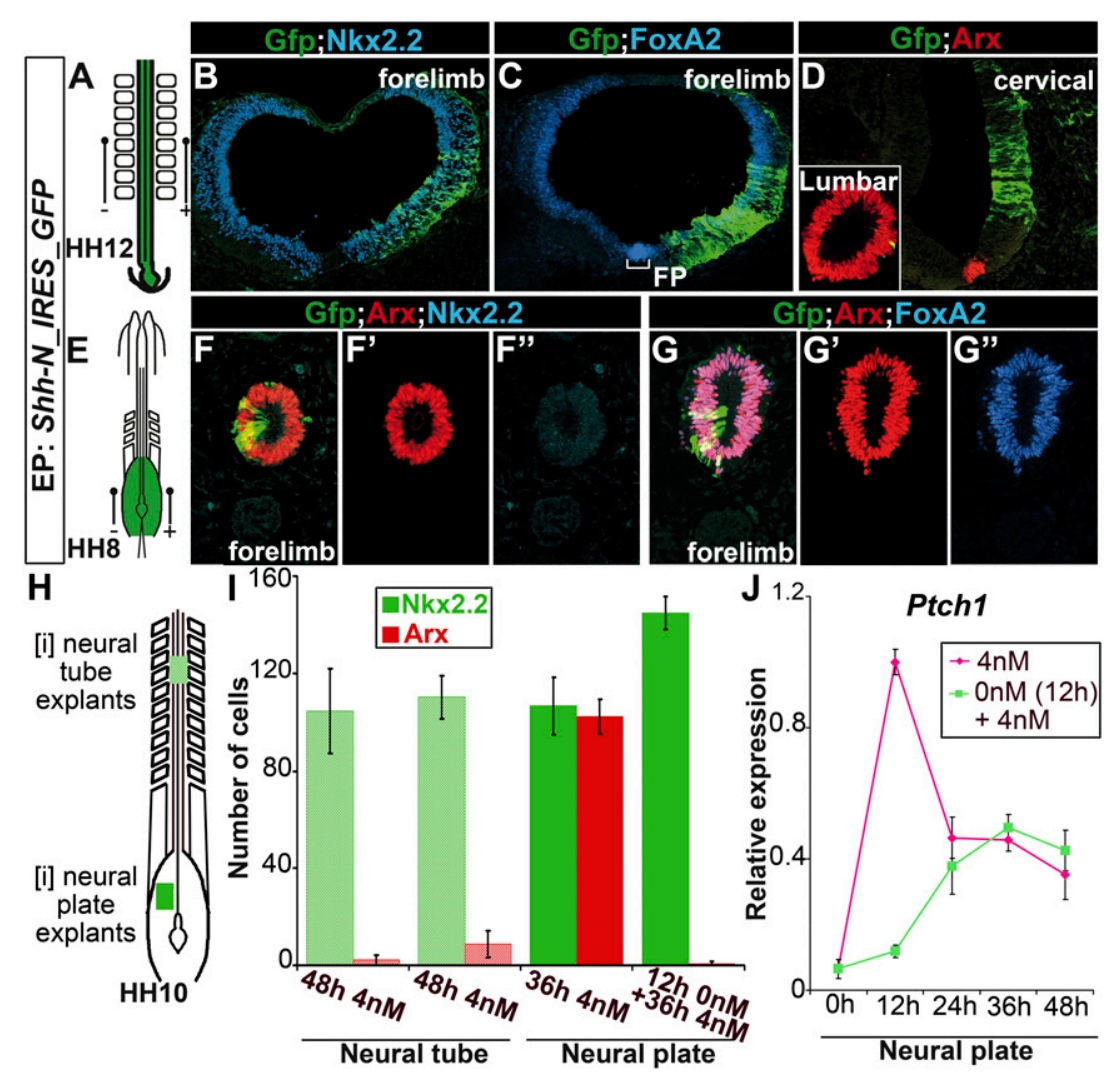

Figure 4. Temporal restriction to FP induction in vivo. $(A, E)$ Schematic of electroporation performed in chick embryos at HH12 and HH8, respectively. $\left(B-D, E-F^{\prime \prime}\right)$ Expression of Arx, FoxA2, Nkx2.2, and Gfp in chick embryos electroporated with $\operatorname{ShhN}$. ShhN induces a p3 identity at brachial levels of HH12 embryos (B$D$ ), but only induces FP markers more caudally (inset in $D$ ). $\left(E-G^{\prime \prime}\right)$ In contrast, in $\mathrm{HH} 8$ embryos, it activates FP markers along the rostral-caudal axis. (H) Schematic of HH10 chick embryos indicating the position of [i-nt] and neural plate [i] explants. (I) Quantification of cells expressing Arx and Nkx2.2 in [i] or [i-nt] explants after 36 or $48 \mathrm{~h}$ of culture $(n \geq 4$, number of cells per unit \pm SD). [i-nt] explants do not express FP markers when exposed to high concentrations of Shh. Likewise, [i] explants do not express Arx when cultured in media devoid of Shh for $12 \mathrm{~h}$ before being transferred to high concentrations of Shh. (J) Temporal dynamics of Ptch1 expression relative to Actin levels assayed by RT-PCR in [i] explants exposed to $4 \mathrm{nM}$ Shh from the start of the culture (pink) or after $12 \mathrm{~h}$ (pale green) $(n=2$, mean $\pm \mathrm{SD}$ ). [i] neural plate explants do not produce the high peak of Ptch1 expression when initially exposed to a media devoid of Shh. to Shh signaling. To test this hypothesis, we expressed $S h h N$ earlier in the ontogeny of neural cells. In ovo electroporation of $S h h N$ in the neural plate of HH8 chick embryos resulted in the exclusive expression of FP markers Arx and FoxA2 along the entire spinal cord. Moreover, the electroporated cells adopted a wedgeshaped morphology reminiscent of the FP (Fig. 4F-G"). Markers of neural progenitors that are normally generated dorsal to the FP, including Nkx2.2, were absent (Fig. $4 \mathrm{~F}^{\prime \prime}$; data not shown). These results indicate that neural progenitors progressively lose their ability to induce a FP identity in response to Shh.

To investigate whether signals from adjacent tissues were responsible for this loss of competence, we isolated explants from the intermediate neural tube ([i-nt $]$ ) of $\mathrm{HH} 12$ chick embryos (Fig. 4H). These explants, which comprised the pMN and $\mathrm{p} 2$ progenitor domains (data not shown), were cultured with $4 \mathrm{nM}$ Shh. In contrast to [i] explants from the open neural plate, none of the [i-nt] explants expressed Arx after exposure to Shh. Nonetheless, induction of Nkx2.2 was observed (Fig. 4I). These results raise the possibility that the change of competence to generate FP cells is intrinsic to neural cells. To test this idea, we cultured [i] explants for $12 \mathrm{~h}$ in media devoid of Shh, followed by $36 \mathrm{~h}$ in the presence of $4 \mathrm{nM} \mathrm{Shh}$, and compared this with control conditions in which [i] explants were cultured continuously for $36 \mathrm{~h}$ in the presence of $4 \mathrm{nM}$ Shh. In controls, $>50 \%$ of the cells assayed at $36 \mathrm{~h}$ had acquired a FP identity (Fig. 4I). In contrast, when addition of Shh was delayed by $12 \mathrm{~h}$, cells adopted a $\mathrm{p} 3$ identity (Fig. 4I). Similarly, cells within [i] explants exposed first to $1 \mathrm{nM}$ Shh for $12 \mathrm{~h}$ and then to $4 \mathrm{nM}$ Shh for $36 \mathrm{~h}$ were not able to adopt a FP character (Supplemental Fig. S4C-E). This supports the idea that, over time, neural progenitors intrinsically lose their ability to acquire a FP identity in response to high levels of Shh.

To address whether the loss of ability to generate FP correlated with a change in the response of cells to Shh signaling, we analyzed the expression of Ptch1 in [i] explants in which the addition of $4 \mathrm{nM}$ Shh was delayed 12 h (Fig. 4J). Strikingly, in these conditions, Ptch1 exhibited a profile of expression similar to the one generated when [i] explants were cultured in the presence of 1 nM of Shh (cf. Figs. 4J and 2F). Notably, the peak level of Ptch1 expression was half that generated in explants exposed to $4 \mathrm{nM}$ Shh from the start of the culture period (Fig. $4 \mathrm{~J}$ ).

Together, these data provide evidence that the response of cells to high concentrations of Shh varies during the course of development. Initially, high concentrations of Shh direct cells toward a FP identity. However, cells progressively lose their ability to translate these concentrations into the highest levels of intracellular signaling; as a consequence, cells are directed toward $\mathrm{p} 3$ identity. As Shh distribution extends gradually throughout the neural tube (Chamberlain et al. 2008), this mechanism is likely to contribute to the restriction of FP to the midline of the neural tube (see the Discussion). 
Specification of FP cells requires down-regulation of Shh signaling

Although high levels of Shh signaling are required for FP induction, the subsequent down-regulation of signaling in presumptive FP cells raised the question of whether inhibition of Gli activity is required for the elaboration of FP identity. To test this, we sustained Shh signaling in FP cells by expressing, in ovo, a dominant active form of Gli3 (Gli3 ${ }^{\mathrm{HIGH}}$ ) in the midline of HH12 chick embryos (Stamataki et al. 2005). This construct results in the ectopic expression of the Shh target Ptch1 at $48 \mathrm{~h}$ post-electroporation (hpe) (Fig. 5C). Strikingly, Arx expression was cellautonomously extinguished within the midline of electroporated embryos at both time points (Fig. 5A,A"'; data not shown), while FoxA2 levels of expression were reduced (Fig. 5B, $\mathrm{B}^{\prime}$ ). Concomitant with this, expression of Nkx2.2 was ectopically induced at low levels at 24 hpe (data not shown), and, by 48 hpe, Nkx2.2 was strongly expressed in transfected cells within the midline of the neural tube (Fig. $\left.5 \mathrm{~A}, \mathrm{~A}^{\prime \prime}\right)$. These data indicate that the down-regulation of Shh signaling is required for the elaboration of FP identity; sustained Shh signaling results in cells acquiring a p3 identity.

We then assessed at which level the Shh pathway is blocked by looking at the effect of transfecting a dominant active form of Smo (Smo-M2) (Hynes et al. 2000) into the midline of HH12 chick embryos. In ovo electroporation of this construct did not inhibit the expression of Arx or FoxA2, and no ectopic Nkx2.2 expression was induced in
FP cells (Fig. 5D-E'). Accordingly, the expression of Ptch1 was not ectopically induced in midline cells transfected with Smo-M2 (Fig. 5F). Nevertheless, Smo-M2 induced ectopic Ptch1 and Nkx2.2 expression in more dorsal regions of the neural tube, as expected (data not shown). These data provide evidence that the loss of the response of FP cells to Shh signaling occurs downstream from Smo.

We therefore tested whether Gli transcription factors, which relay Shh signaling, are present in the FP cells. Midline cells appear to be devoid of Gli3 expression (data not shown) at all time points analyzed, consistent with previous reports (Marigo et al. 1996). In contrast, Gli2 expression is dynamic. At E8.0, Gli2 was expressed in cells of the ventral midline, but its expression was downregulated in these cells from 18ss, while being maintained more dorsally (Fig. 5G-J; Bai et al. 2002; data not shown). Similarly, FP cells in HH18 chick embryos lacked Gli2 expression (Fig. 5J). In order to assess whether the down-regulation of Gli2 was required for the appearance of definitive FP markers, we electroporated this transcription factor into the midline of $\mathrm{HH} 12$ chick embryos. This resulted in the down-regulation of FoxA2 expression and extinction of Arx (Fig. 5K-L). Moreover, ectopic expression of Nkx2.2 was observed in some cells expressing Gli2, albeit less frequently than in Gli3 ${ }^{H I G H}$ transfected cells (Fig. 5K-K"'; data not shown). Together, these data demonstrate that the down-regulation of Shh signaling is essential for the emergence and maintenance of the FP.

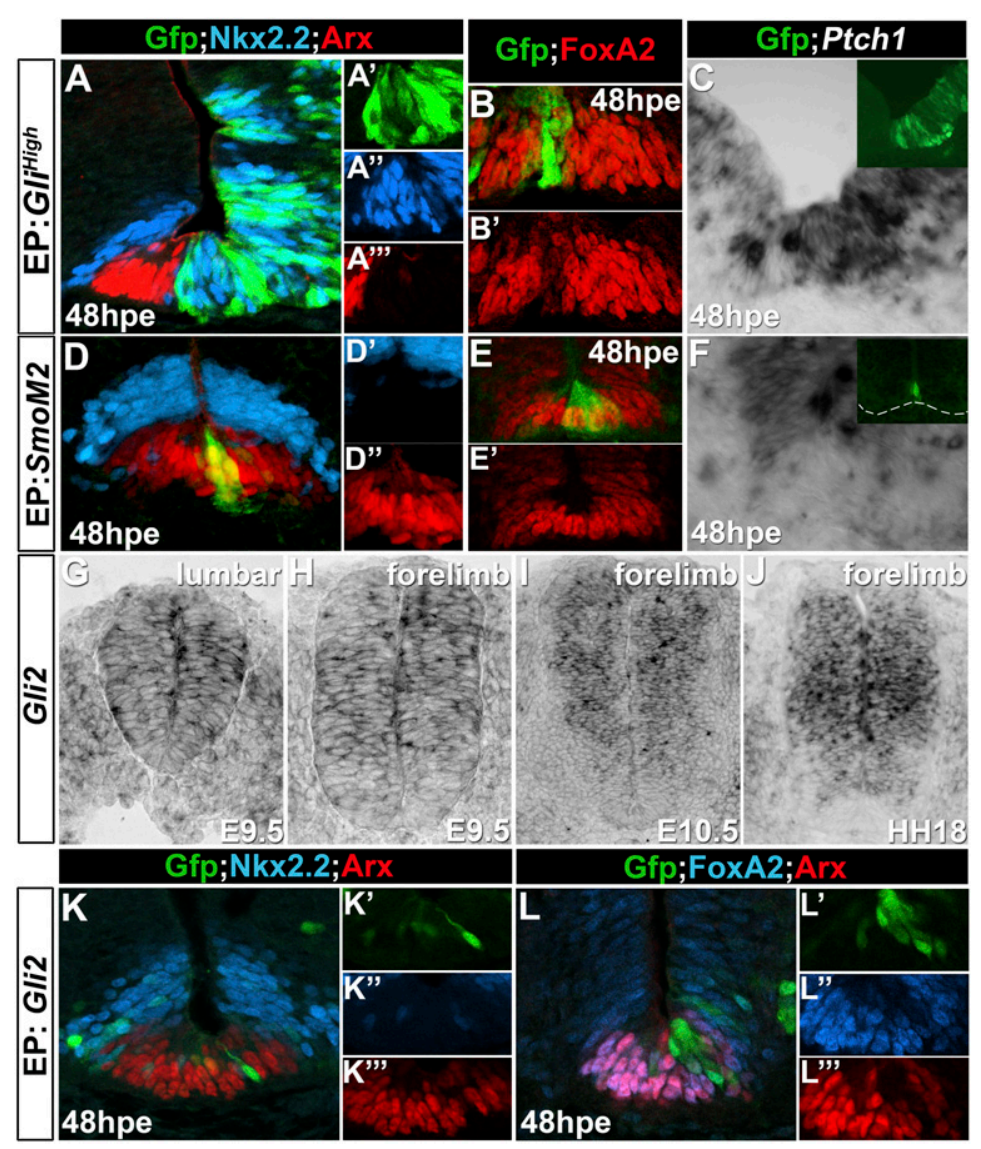

Figure 5. Down-regulation of Shh signaling is required for the expression of definitive FP markers. $(A-F)$ Transfection of Gli3 ${ }^{H I G H}$ and SmoM2 in the ventral midline of HH11-12 chick embryos assayed for Arx, Nkx2.2, FoxA2, GFP, and Ptch1 expression 48 hpe. Gli3 ${ }^{H I G H}$ switches FP cells into a p3 identity $(A-C)$, while $S m o M 2$ does not affect the fate of these cells $(D-F)$. $(G-J)$ Expression of Gli2 in E9.5 and E10.5 mouse $(G-I)$ and HH18 chick $(J)$ embryos. Gli2 expression is progressively down-regulated from ventral midline cells in amniotes. $\left(K-L^{\prime \prime}\right)$ Gli2 electroporated into ventral midline cells of $\mathrm{HH} 12$ chick embryos, assayed for Arx, Nkx2.2, FoxA2, and GFP expression 48 hpe. Similar to Gli3 ${ }^{H I G H}$, Gli2 down-regulates the expression of FP markers and induces Nkx2.2 expression. 
Ribes et al.

The transcription factor FoxA2 relays Shh signaling during the later steps of FP specification

The down-regulation of Shh signaling in presumptive FP cells occurs prior to the induction of definitive markers of FP identity, raising the question of how Shh signaling is relayed to instruct the later steps in FP specification. FoxA2 was a good candidate for this, as it is a direct target of Shh signaling (Sasaki et al. 1997) and loss-of-function mutants in zebrafish exhibit transient specification defects in FP identity (Norton et al. 2005). Whether FoxA2 has a similar function in the amniotes has been obscured by the early gastrulation defects present in FoxA2 mutant mice (Ang and Rossant 1994; Weinstein et al. 1994).

To test the function of FoxA2 during FP specification, we first expressed a dominant-negative form of FoxA2, FoxA2$E n R$ (see the Material and Methods), in the ventral neural tube of HH11-12 chick embryos, a stage when FoxA2 is strongly expressed within the ventral neural tube (data not shown). In ovo electroporation of this construct cell-autonomously abolished Arx expression and resulted in the ectopic expression of Nkx2.2 in these cells (Fig. 6A, $\mathrm{A}^{\prime}$ ). Thus, FoxA2 is required in amniotes, as in anamniotes, for FP identity. Conversely, forced expression of FoxA2 in HH1 1-12 chick embryos is sufficient to induce Arx expression by 48 hpe (Fig. 6C-D'). Notably, FoxA2 electroporation resulted in the induction of $\mathrm{Nkx} 2.2$ expression in a noncell-autonomous manner 24 and 48 hpe (Fig. 6C,D). The ectopic expression of $\mathrm{Nkx} 2.2$ is likely due to the induction of Shh expression by FoxA2 (Fig. 6E; Jacob et al. 2007).

The induction of Shh expression by FoxA2 raised the possibility that Shh signaling might be required for FoxA2 to induce Arx expression and a FP identity. To address this question, we coexpressed FoxA2 with Ptc1 ${ }^{\text {4loop2 }}$ in HH11-12 chick embryos. The inhibition of Shh signaling in cells expressing FoxA2 did not affect the ability of FoxA2 to induce Arx expression (Fig. 6G). Thus, FoxA2 promotes FP fate independently of Shh signaling. Moreover, by 48 hpe, Ptch1 expression was down-regulated in cells transfected with FoxA2 (Fig. 6F). Conversely, Ptch1 expression was ectopically induced in FP cells by FoxA2EnR (Fig. 6B). This suggests that FoxA2 is involved, directly or indirectly, in the down-regulation of Shh signaling within midline cells that is necessary for FP development. Consistent with this, although the expression of Smo-M2 alone was sufficient to induce ectopic Nkx2.2 expression and a Shh response in progenitors (Fig. 6H,I; Hynes et al. 2000), cotransfection of Smo-M2 and FoxA2 blocked Shh response and Nkx2.2 induction (Fig. $6 \mathrm{I}, \mathrm{J})$. Together, these data provide evidence that FoxA2 is a key factor that relays Shh signaling during FP development. It is necessary and sufficient to induce definitive FP markers, and may control the dynamics of Shh signaling in midline cells by regulating the expression of target genes that modulate the expression of components of the Shh signal transduction pathway.

\section{Discussion}

Shh was initially identified as the key extrinsic cue for FP development (Chiang et al. 1996; Ericson et al. 1996).

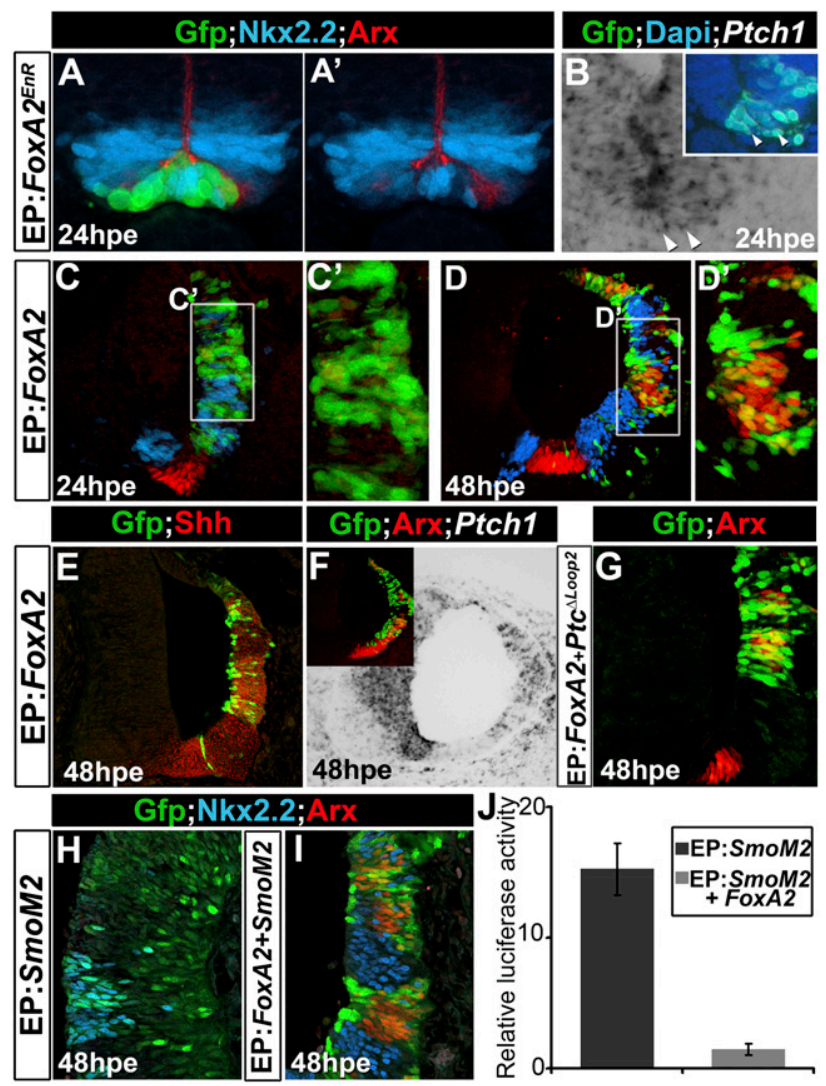

Figure 6. Shh signaling relayed by FoxA2 during FP specification. $(A-F)$. Transfection of FOXA2 and FoxA2EnR in HH11-12 chick embryos assayed for Arx, Nkx2.2, Shh, Ptch1, and GFP expression 24 and 48 hpe. FOX $A 2^{E n R}$ blocks FP specification and induces Ptch1 expression. Conversely, FoxA2 is sufficient to induce Arx and Shh expression and to down-regulate Ptch1 expression. $(G)$ Coelectroporation of FoxA2 and Ptc1 $1^{\text {sloop2 }}$ in HH11-12 chick embryos assayed for Arx after 48 hpe indicates that FoxA2 is able to induce FP identity independently of Shh signaling. $(H, I)$ Electroporation of SmoM2 alone or together with FoxA2 assayed for Arx and Nkx2.2 48 hpe. FoxA2 inhibits the ability of SmoM2 to induce ectopic p3 cells. (J) Gli activity (relative activity \pm SEM) measured with GBS-Luc reporter in HH11-12 chick neural tube electroporated with GFP or SmoM2, either alone or together with FoxA2. FoxA2 inhibits the ability of SmoM2 to induce Gli activity.

However, there has been a considerable debate as to the exact function of Shh in FP specification. First, its requirement does not appear to be evolutionarily conserved among all vertebrates (Strahle et al. 2004). Second, some studies have questioned the ability of Shh to induce FP robustly in neural tissue (e.g., Charrier et al. 2002; Patten and Placzek 2002). Our study addresses these issues and provides evidence that FP specification relies on a biphasic response of cells to Shh signaling in a range of vertebrate species, including zebrafish (Fig. 7A). In agreement with the prevailing view of Shh-mediated pattern formation (Ericson et al. 1996), we show that high levels of Shh signaling are essential for FP specification. However, the timing of Shh exposure is critical, as the competence of neural progenitors to become FP cells is limited 
A

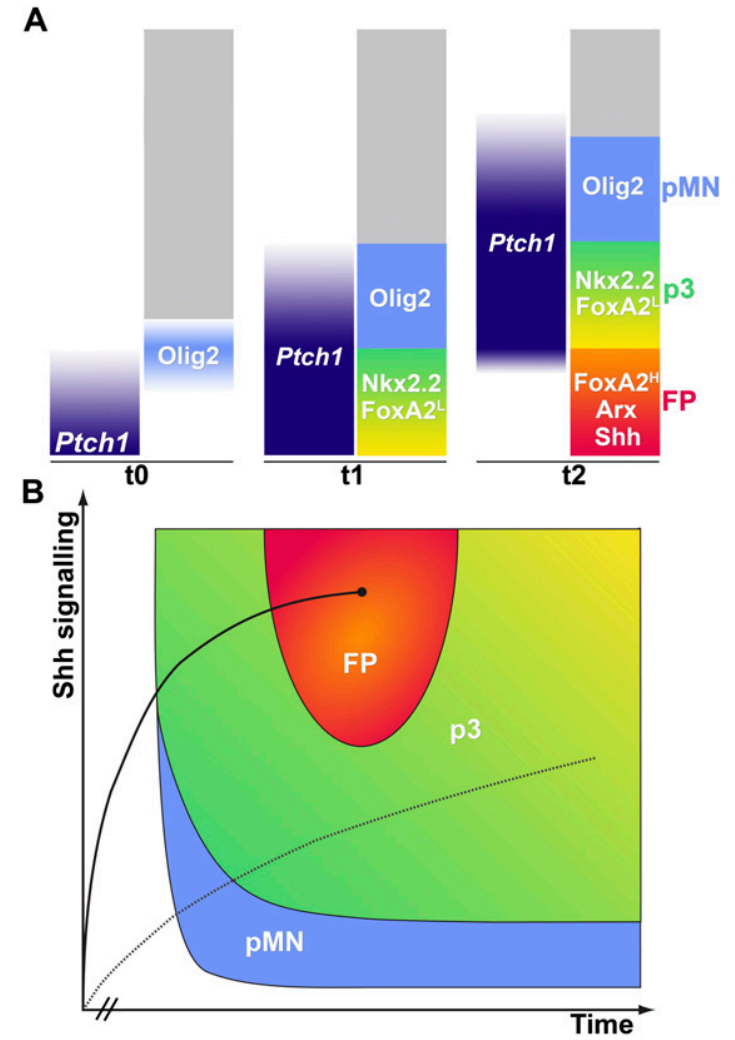

Figure 7. Dynamics of FP specification. (A) A schematic of the dynamics of signaling and gene expression profiles within the ventral neural tube. At early times (t0), the Shh target gene Ptch1 is restricted to the most ventral cells, and the pMN marker Olig2 is initiated in cells at a distance from the ventral midline. At later times (t1), Ptch1 and Olig2 expression expand dorsally; the p3 progenitor markers $\mathrm{Nkx} 2.2$ and low levels (L) of FoxA2 are induced in the ventral midline. Subsequently (t2), p3 and pMN domains shift dorsally, and Ptch1 is down-regulated in midline cells; at the same time, midline cells adopt a definitive FP identity expressing high $(\mathrm{H})$ levels of FoxA2, Arx, and Shh. $(B)$ State space map of neural progenitors' response to Shh signaling. FP (red) requires high but transient Shh signaling early in development, while p3 identity (green) can be induced by Shh signaling at later times. The dashed line represents the path of a p3 precursor cell, and the solid line represents the path of a FP precursor cell. Cells exposed to high levels of Shh signaling early in development initially express $\mathrm{Nkx} 2.2$ before inducing definitive FP markers such as Arx. Importantly, the acquisition of a FP state results in cells becoming refractory to Shh signaling (represented by the solid circle); however, if signaling is maintained artificially, these cells acquire a p3 identity. In contrast, a neural progenitor initially exposed to a lower level of signaling first adopts a pMN identity (blue). If the level of signaling is appropriate, the cell then transitions into a p3 identity, and this identity is kept if sufficient signaling levels are maintained.

to gastrulation and early somitogenesis stages. Progenitors receiving high levels of signaling outside this time window adopt a p3 neural progenitor identity. Subsequently, however, the elaboration of FP identity requires the duration of Shh signaling to be time-restricted, and sustained signaling within prospective FP progenitors leads them to adopt a 3 identity. Thus, three parameters-the level, timing, and duration of Shh signaling - distinguish FP cells from other ventral neural progenitors and control distinct transcriptional programs in these cell types.

\section{A unified scheme for FP specification by Shh signaling in vertebrates}

Two contrasting models of FP development have been formulated (for reviews, see Le Douarin and Halpern 2000; Placzek et al. 2000; Strahle et al. 2004; Placzek and Briscoe 2005). In the first, FP cells are specified by an inductive signal, Shh, secreted from the notochord. This model stipulates that Shh induces FP development in a manner analogous to its role in the induction and patterning of ventral neural progenitors (Placzek et al. 2000; Placzek and Briscoe 2005). Accordingly, FP induction is proposed to be the consequence of exposure to the highest levels of Shh. In the second model, the induction of FP cells occurs within the organizer/node during gastrulation, and is independent of more anterior interactions between the notochord and the ventral neural plate (Le Douarin and Halpern 2000; Strahle et al. 2004; Placzek and Briscoe 2005). In this model, Shh has little, if any, role in inducing FP identity (Varga et al. 2001), or it acts as a permissive, or survival, signal that prevents apoptosis of FP precursors (Charrier et al. 2001).

Our data strongly support the first model, and indicate that Shh signaling is both necessary and sufficient for the induction of FP identity in amniotes, consistent with previous loss- and gain-of-function studies (Placzek et al. 1991; Roelink et al. 1995; Chiang et al. 1996; Ericson et al. 1996). Importantly, however, our data identify a restricted developmental time window, spanning gastrulation and early somitogenesis stages, when Shh signaling is able to trigger the emergence of FP identity within the open neural plate. This suggests an explanation for studies that failed to find a requirement of the notochord or Shh in FP induction (Le Douarin and Halpern 2000; Strahle et al. 2004). Indeed, exposure of chick neural cells to Shh after the initiation of somitogenesis does not induce FP formation (Teillet et al. 1998; Charrier et al. 2002; Patten and Placzek 2002), and removal of notochord in chick embryos does not disrupt FP formation along most of the embryonic axis (van Straaten et al. 1989; Yamada et al. 1991; Teillet et al. 1998).

How the time window during which Shh signaling is able to induce FP development is defined remains to be determined. However, the mechanism appears to be autonomous to neural tissue. Both anterior neural tube explants deprived of surrounding tissues and neural plate explants cultured for $12 \mathrm{~h}$ in medium lacking sufficient Shh are unable to give rise to FP cells in response to Shh signaling. One possibility is that an intrinsic clock is established within newly induced neural cells, and this sets a time limit for how long Shh is able to promote FP identity. However, this does not exclude the possibility that the competence of cells to generate FP might depend on interactions with signaling pathways active within neural tissue. For example, signals emanating dorsally, 
such as Wnts and bone morphogenetic proteins (BMPs), might affect the ability of cells to respond to Shh (Dale et al. 1999; Patten and Placzek 2002; Joksimovic et al. 2009); in this context, it is notable that exposure to the BMP antagonist Chordin enhances the ability of Shh to induce FP (Dale et al. 1999; Patten and Placzek 2002). Moreover, regardless of how the change in competence of neural tissue is achieved, this process is likely to be responsible for the restriction of FP markers to the midline of the neural tube. The amplitude of the Shh gradient increases in the spinal cord as development proceeds (Chamberlain et al. 2008). Thus, prospective p3 cells are exposed to at least similar levels of ligand as prospective FP cells; however, the time at which $\mathrm{p} 3$ cells receive these high concentrations of Shh is later than the presumptive FP cells (Chamberlain et al. 2008). This temporal-spatial constraint on when cells are exposed to Shh would thereby provide a mechanism to define the size of the $\mathrm{FP}$, and is reminiscent of the way in which the timing of Wnt signaling determines the size of the heart field (Ueno et al. 2007).

The apparent species differences in FP induction have also led to uncertainty over the molecular mechanism of FP development. Although, in zebrafish, Nodal signaling is credited with the principal role in FP induction, in amniotes, it is likely to play only a minor role. On the one hand, Nodal potentiates the ability of Shh to induce FP identity in the midline of the chick forebrain and midbrain (Patten et al. 2003). On the other hand, FP markers are induced prematurely in the anterior epiblast of E7.5 Nodal ${ }^{-1-}$ mouse embryos (Camus et al. 2006). Moreover, FP induction is observed in mouse embryos formed from cells deficient for nodal (Varlet et al. 1997) or its downstream effector, Smad2 (Heyer et al. 1999), or treated with a nodal inhibitor (data not shown). In contrast to Nodal, our data suggest that the role of Shh signaling during FP specification in teleosts and amniotes shares several features. The transience of Shh signaling within FP progenitors indicated by the temporal profile of the expression of the Shh target genes Gli1 and Ptch1 is similar in the FP of amniotes and zebrafish species (Fig. 2; Concordet et al. 1996; Lewis et al. 1999; Karlstrom et al. 2003). Moreover, in each species tested, FP development requires Shh signaling during a time window that spans gastrulation and early somitogenesis (Fig. 3). Importantly, this time window coincides with when Nodal signaling is required for zebrafish FP induction (Tian et al. 2003). Furthermore, FP-inducing signals appear to converge on the regulation of FoxA2 in teleosts and amniotes (Strahle et al. 1993; Sasaki et al. 1997; Muller et al. 2000). Taken together, the data indicate that, in all vertebrates, FP induction takes place in a brief time window during the course of gastrulation, and the extrinsic signals involved in this process regulate FoxA2 expression. The difference between species resides mainly in the relative contribution of each signal. It is therefore tempting to hypothesize that both Shh and Nodal signals were involved in FP specification in the common ancestor of vertebrates. Subsequently, the relative importance of each signal changed during the evolution of individual species (see also Rastegar et al. 2002). Detailed analysis of the regulatory elements directing expression of FoxA2 in different species should shed further light on this hypothesis (Sasaki et al. 1997).

\section{Distinct dynamics of Shh signaling specify FP cells}

FP development is triggered by high levels of Shh that result in the rapid induction of Nkx2.2 and Foxa2. In contrast, cells fated to generate the adjacent $\mathrm{p} 3$ progenitor domain are initially exposed to lower levels of signaling, and induce Olig2 prior to Nkx2.2. However, the full elaboration of FP identity relies on a subsequent decrease in intracellular Shh signaling because FP cells switch to a p3 identity if signaling is artificially sustained. Thus a dynamic transcriptional program, produced by the different levels and timing of signaling, distinguishes FP cells from p3 progenitors. How is the appropriate profile of Shh signaling achieved in the FP? During gastrulation and early somitogenesis, the concentration of Shh in neural tissues is low (Chamberlain et al. 2008). Nevertheless, the low levels of the negative regulator of Shh signaling, Ptch1, in neural tissue at these early times may allow the induction of high levels of signaling in response to low amounts of Shh. In addition, the Shh-interacting transmembrane proteins Gas1 and Cdo may sensitize progenitors to Shh (Allen et al. 2007; Martinelli and Fan 2007). Embryos mutant for both Cdo and Gas1 lack FP induction, and the forced expression of these factors in chick neural tube is sufficient to direct cell-autonomous $\mathrm{p} 3$ cells toward a FP identity (Tenzen et al. 2006; Allen et al. 2007; data not shown). Importantly, the expression of these proteins is tightly regulated. In the ventral neural tube, Cdo transcripts are restricted to FP cells between E9.0 and E11.5. Gas1 is first induced throughout the neural tube at E8.5, and becomes progressively down-regulated within the ventral neural tube. Prior to E9.5, therefore, prospective FP cells express the signal enhancers $C d o$ and Gas1 (Tenzen et al. 2006; Allen et al. 2007).

The later decrease in signaling as FP identity is elaborated might be partly explained by the rapid downregulation of Gas1. In addition, the repression of Gli2 expression is likely to be essential. Gli2 plays the predominant role in relaying the Shh signal during FP induction (Matise et al. 1998; Bai and Joyner 2001; Bai et al. 2002), and its expression profile follows the dynamics of Shh signaling in the midline of both chicks and mice (Fig. 5; Bai and Joyner 2001; Lei et al. 2004). Thus repression of Gli2, and possibly other components of the Shh signaling pathway, in FP cells provides a mechanism that would result in the extinction of signaling in these cells. The down-regulation of these factors appears to be triggered by the transcription factor FoxA2 (Fig. 6; data not shown). This suggests a model in which Shh signaling directly induces expression of FoxA2 (Sasaki and Hogan 1994), which then induces the expression of Shh itself (Ruiz i Altaba et al. 1995; Chang et al. 1997; Jeong and Epstein 2003) and participates in the extinction of Shh signaling within these cells, perhaps by inducing target genes that directly regulate components of the Shh signal transduction pathway. It is noteworthy that other 
forkhead transcription factors-including Foxp2, Foxp4, and Foxj1-are expressed in FP cells (Takahashi et al. 2008; Yu et al. 2008; Morikawa et al. 2009; data not shown), raising the possibility that several members of this family participate in shaping the sensitivity of FP cells to Shh signaling.

\section{A common strategy of morphogen interpretation for the generation of cellular diversity}

The distinct dynamics of Shh signaling that are required for FP development add a new dimension to the interpretation of the Shh morphogen. Previous studies in the neural tube suggested that concurrent increases in the level and duration of Shh signaling lead to the progressive specification of cell identities (Ericson et al. 1996; Jeong and McMahon 2005; Dessaud et al. 2007). In contrast, the data presented here indicate that cells exposed to the highest Shh concentrations at early developmental times generate a transient peak of signaling activity and produce FP. Then, at later times, cells transform increasing concentrations of Shh into longer periods of signaling to generate progressively more ventral neural progenitor domains (Dessaud et al. 2007). This identifies two modes of Shh morphogen interpretation (Fig. 7A,B). These two modes also appear to be deployed in other tissues. In the vertebrate limb bud, Gli activity exhibits a spatial and temporal gradient within the precursors of digits 2-4 (Ahn and Joyner 2004). Accordingly, the specification of these structures requires a prolonged exposure to Shh, such that digit 4 requires the longest exposure (Towers et al. 2008; Zhu et al. 2008). In contrast, the specification of digit 5 appears similar to the specification of FP by Shh signaling. The precursors of this digit, although exposed to high levels of Shh early in development, become independent of Shh signaling much sooner than other digit precursors (Zhu et al. 2008). Moreover, a down-regulation of the Shh target genes Gli1 and Ptch1 in the precursors of this digit (Ahn and Joyner 2004) is accompanied by an inhibition of Gli2 expression (Marigo et al. 1996). Furthermore, similar to FP cells, digit 5 precursors act as a source of Shh (Harfe et al. 2004). In the Drosophila wing disc, Hh protein secreted from the posterior compartment induces the transcription factor engrailed (En) in a small territory in the anterior compartment (Strigini and Cohen 1997; Basler 2000). Expression of En has been associated with the down-regulation of Ptch and Ci (Basler 2000). Thus, by analogy to vertebrates, it is possible that cells responding to the highest levels of $\mathrm{Hh}$ signaling in the anterior compartment become refractory to the signal. Together, the data suggest a general means to augment the role of a morphogen. This strategy can be used in a wide range of development settings and can be elaborated further, as exemplified by the triphasic (Off-On-Off) response of ventral pancreatic precursors to BMP-Smad4 signaling (Wandzioch and Zaret 2009). Exploiting the dynamics of signal responses in this way extends the potential of a single signal to control differential transcriptional programs and cell identity during embryogenesis.

\section{Materials and methods}

Immunohistochemistry and in situ hybridization

Antibody reagents and protocols have been described elsewhere (Ericson et al. 1997; Briscoe et al. 2000, 2001). The antibody for Arx was kindly provided by J. Chelly (Poirier et al. 2004). Analysis was carried out using a Leica TCS SP2 confocal microscope and processed with Adobe Photoshop 7.0 software (Adobe Systems). In situ hybridization was performed as described (chicks and mice: Chotteau-Lelièvre et al. 2006; zebrafish: Thisse et al. 1993) using the following probes: chick Ptch1 and Gli1-3 (C. Tabin); mouse Ptch1 and Gli1-3 (C.C. Hui); zebrafish foxa2 (axial) and shh (P. Ingham).

\section{Chick in ovo electroporation}

All electroporation constructs were based on pCAGGS expression vector engineered to bicistronically express nuclear targeted GFP (pCAGGS-IRES NLS-GFP). Gli3A $A^{\text {High }}$ (Stamataki et al. 2005), Gli2 (Schweitzer et al. 2000), Ptc1 ${ }^{\text {4loop2 }}$ (Briscoe et al. 2001), SmoM2 (Hynes et al. 2000), FoxA2 (Ferri et al. 2007), FoxA2 ${ }^{\text {EnR }}$ (Jacob et al. 2007), and ShhN (Roelink et al. 1995) have been described previously. HH8-12 embryos were electroporated and incubated in ovo before dissecting and processing for either immunohistochemistry or in situ hybridization.

\section{Luciferase reporter assays}

Luciferase measurements were performed using the Dual-Luciferase Reporter Assay System (Promega). Expression plasmids or empty vector were electroporated into HH10-12 chick embryos together with the GBS-Luc firefly luciferase reporter (Sasaki et al. 1997) and a Renilla luciferase reporter driven by a CMV promoter (Promega) for normalization. Assays were performed as described previously (Stamataki et al. 2005).

\section{Neural explants and RT-PCR}

Explants isolated from HH10 chick embryos were cultured as described (Yamada et al. 1993; Ericson et al. 1997). Cyclopamine (Toronto Research Chemicals) was dissolved in $96 \%$ ethanol. RNA was extracted using PicoPure RNA Isolation kit (Arcturus). cDNA was synthesized by SuperScriptII (Invitrogen) and quantitative PCR was performed using an ABI7500. The expression of each gene was normalized to that of Actin. The following oligonucleotides were used: Actin, (fw) GAGAAATTGTGCGTGA CATCA and (rev) CCTGAACCTCTCATTGCCA; Ptch1, (fw) TTTTTCTTTTCCTGGGCTTACTT and (rev) CATCTCTACC CGGGTAGTTC; $N k x 2.2$, (fw) ACCTTCCAAACGGGCATC and (rev) TGTAATGGGCGTTGTATTGC; $A r x,(\mathrm{fw})$ TGGCCT CAGTAGCCTTACCT and (rev) AGCATTGAGAAACCTTCC AAA; FoxA2, (fw) AGCAGTCGCCCAACAAGATG and (rev) TCTGGCGGTAGAAGGGGAAG.

\section{Embryo culture experiments}

Mouse embryos with intact yolk sacs, dissected from timed pregnant females, were cultured for $24 \mathrm{~h}$ in medium (rat serum, Tyrode solution; $1: 1$ between E7.5 and E8.5; 2:1 at E9.5) in 8-mL tubes ( $2.5 \mathrm{~mL}$ of medium per tube; three embryos per tube). Cyclopamine was used at a concentration of $5-10 \mu \mathrm{M}$ as indicated. Cultures were performed in a water-saturated roller-tube incubator at $37^{\circ} \mathrm{C}$, $5 \% \mathrm{CO}_{2}$ and $5 \% \mathrm{O}_{2}$ at $\mathrm{E} 7.5,20 \% \mathrm{O}_{2}$ at $\mathrm{E} 8.5$, and $65 \% \mathrm{O}_{2}$ at $\mathrm{E} 9.5$. After culture, embryos were fixed and processed. Gene expression patterns were always compared between embryos processed in the same culture experiment in appropriate control conditions. 


\section{Zebrafish embryos and drug treatments}

Wild-type zebrafish embryos or cyclops mutant fish (Hatta et al. 1991) were treated with vehicle $\left(\mathrm{EtOH}^{+}\right.$and/or DMSO) and $5 \mu \mathrm{M}$ cyclopamine (Toronto Research Chemicals; stock solution at 10 $\mathrm{mM}$ was prepared in $96 \% \mathrm{EtOH}$ ) at either $30 \%$ epiboly stage or at 16ss, and with $800 \mu \mathrm{M}$ SB431542 at 30\% epiboly stage (Sigma; stock solution at $60 \mathrm{mM}$ in DMSO; Hagos and Dougan 2007) dissolved in Danieau solution. There were no differences in the neural expression of axial and shh between untreated and vehicletreated embryos.

\section{Acknowledgments}

We thank members of the laboratory, especially Natascha Bushati, John Jacob, and Euginia Piddini for helpful comments and discussions. We are grateful to C.C. Hui for Ptch1 mutant embryos. We also thank Biological Services staff at NIMR for help with the mouse colonies. We thank T. Jessell, B. Han, and M. Mendelsohn for generating Olig2-cre mice, and the UCL Fish Facility for supplying cyclops mutant fish. V.R. and S.T. are supported by EMBO LTFs and N.S. is supported by Marie Curie Fellowship. Work in the laboratory of J.B. is supported by the MRC (UK) and the Wellcome Trust (grant 080630). Work in the E.M. laboratory is supported by the Spanish Ministry of Education grant BFU2004-00455/BMC.

\section{References}

Ahn S, Joyner AL. 2004. Dynamic changes in the response of cells to positive hedgehog signaling during mouse limb patterning. Cell 118: 505-516.

Albert S, Muller F, Fischer N, Biellmann D, Neumann C, Blader P, Strahle U. 2003. Cyclops-independent floor plate differentiation in zebrafish embryos. Dev Dyn 226: 59-66.

Allen BL, Tenzen T, McMahon AP. 2007. The Hedgehog-binding proteins Gas1 and Cdo cooperate to positively regulate Shh signaling during mouse development. Genes Dev 21: 12441257.

Ang SL, Rossant J. 1994. HNF-3 $\beta$ is essential for node and notochord formation in mouse development. Cell 78: 561574.

Bai CB, Joyner AL. 2001. Gli1 can rescue the in vivo function of Gli2. Development 128: 5161-5172.

Bai CB, Auerbach W, Lee JS, Stephen D, Joyner AL. 2002. Gli2, but not Glil, is required for initial Shh signaling and ectopic activation of the Shh pathway. Development 129: 47534761.

Basler K. 2000. EMBO gold medal 1999. Waiting periods, instructive signals and positional information. EMBO $J$ 19: 1168-1175.

Briscoe J, Pierani A, Jessell TM, Ericson J. 2000. A homeodomain protein code specifies progenitor cell identity and neuronal fate in the ventral neural tube. Cell 101: 435-445.

Briscoe J, Chen Y, Jessell TM, Struhl G. 2001. A hedgehoginsensitive form of patched provides evidence for direct longrange morphogen activity of sonic hedgehog in the neural tube. Mol Cell 7: 1279-1291.

Camus A, Perea-Gomez A, Moreau A, Collignon J. 2006. Absence of Nodal signaling promotes precocious neural differentiation in the mouse embryo. Dev Biol 295: 743-755.

Chamberlain CE, Jeong J, Guo C, Allen BL, McMahon AP. 2008. Notochord-derived Shh concentrates in close association with the apically positioned basal body in neural target cells and forms a dynamic gradient during neural patterning. Development 135: 1097-1106.
Chang BE, Blader P, Fischer N, Ingham PW, Strahle U. 1997. Axial (HNF3 $\beta$ ) and retinoic acid receptors are regulators of the zebrafish sonic hedgehog promoter. EMBO I 16: 39553964.

Charrier JB, Lapointe F, Le Douarin NM, Teillet MA. 2001. Antiapoptotic role of Sonic hedgehog protein at the early stages of nervous system organogenesis. Development 128: 40114020.

Charrier JB, Lapointe F, Le Douarin NM, Teillet MA. 2002. Dual origin of the floor plate in the avian embryo. Development 129: 4785-4796.

Chiang C, Litingtung Y, Lee E, Young KE, Corden JL, Westphal H, Beachy PA. 1996. Cyclopia and defective axial patterning in mice lacking Sonic hedgehog gene function. Nature 383: 407-413.

Chotteau-Lelièvre A, Dollé P, Gofflot F. 2006. Expression analysis of murine genes using in situ hybridization with radioactive and non radioactively labeled probes. In Methods of molecular biology: In situ hybridization protocols 3rd ed.(ed. IA Darby, TD Hewitson), pp. 61-87. Humana Press, Totowa, NJ.

Concordet JP, Lewis KE, Moore JW, Goodrich LV, Johnson RL, Scott MP, Ingham PW. 1996. Spatial regulation of a zebrafish patched homologue reflects the roles of sonic hedgehog and protein kinase A in neural tube and somite patterning. Development 122: 2835-2846.

Cooper MK, Porter JA, Young KE, Beachy PA. 1998. Teratogenmediated inhibition of target tissue response to Shh signaling. Science 280: 1603-1607.

Dale K, Sattar N, Heemskerk J, Clarke JD, Placzek M, Dodd J. 1999. Differential patterning of ventral midline cells by axial mesoderm is regulated by BMP7 and chordin. Development 126: $397-408$.

Davidson EH, Rast JP, Oliveri P, Ransick A, Calestani C, Yuh $\mathrm{CH}$, Minokawa T, Amore G, Hinman V, Arenas-Mena C, et al. 2002. A genomic regulatory network for development. Science 295: 1669-1678.

Dessaud E, Yang LL, Hill K, Cox B, Ulloa F, Ribeiro A, Mynett A, Novitch BG, Briscoe J. 2007. Interpretation of the sonic hedgehog morphogen gradient by a temporal adaptation mechanism. Nature 450: 717-720.

Dessaud E, McMahon AP, Briscoe J. 2008. Pattern formation in the vertebrate neural tube: A sonic hedgehog morphogen-regulated transcriptional network. Development 135: 2489-2503.

Ericson J, Morton S, Kawakami A, Roelink H, Jessell TM. 1996. Two critical periods of Sonic Hedgehog signaling required for the specification of motor neuron identity. Cell 87: 661-673.

Ericson J, Rashbass P, Schedl A, Brenner-Morton S, Kawakami A, van Heyningen V, Jessell TM, Briscoe J. 1997. Pax6 controls progenitor cell identity and neuronal fate in response to graded Shh signaling. Cell 90: 169-180.

Ferri AL, Lin W, Mavromatakis YE, Wang JC, Sasaki H, Whitsett JA, Ang SL. 2007. Foxa1 and Foxa2 regulate multiple phases of midbrain dopaminergic neuron development in a dosagedependent manner. Development 134: 2761-2769.

Goodrich LV, Milenkovic L, Higgins KM, Scott MP. 1997. Altered neural cell fates and medulloblastoma in mouse patched mutants. Science 277: 1109-1113.

Hagos EG, Dougan ST. 2007. Time-dependent patterning of the mesoderm and endoderm by Nodal signals in zebrafish. BMC Dev Biol 7: 22. doi: 10.1186/1471-213X-7-22.

Harfe BD, Scherz PJ, Nissim S, Tian H, McMahon AP, Tabin CJ. 2004. Evidence for an expansion-based temporal Shh gradient in specifying vertebrate digit identities. Cell 118: 517-528.

Hatta K, Kimmel CB, Ho RK, Walker C. 1991. The cyclops mutation blocks specification of the floor plate of the zebrafish central nervous system. Nature 350: 339-341. 
Heyer J, Escalante-Alcalde D, Lia M, Boettinger E, Edelmann W, Stewart CL, Kucherlapati R. 1999. Postgastrulation Smad2deficient embryos show defects in embryo turning and anterior morphogenesis. Proc Natl Acad Sci 96: 12595-12600.

Hynes M, Ye W, Wang K, Stone D, Murone M, Sauvage F, Rosenthal A. 2000. The seven-transmembrane receptor smoothened cell-autonomously induces multiple ventral cell types. Nat Neurosci 3: 41-46.

Incardona JP, Gaffield W, Kapur RP, Roelink H. 1998. The teratogenic Veratrum alkaloid cyclopamine inhibits sonic hedgehog signal transduction. Development 125: 3553-3562.

Jacob J, Ferri AL, Milton C, Prin F, Pla P, Lin W, Gavalas A, Ang SL, Briscoe J. 2007. Transcriptional repression coordinates the temporal switch from motor to serotonergic neurogenesis. Nat Neurosci 10: 1433-1439.

Jeong Y, Epstein DJ. 2003. Distinct regulators of Shh transcription in the floor plate and notochord indicate separate origins for these tissues in the mouse node. Development 130: 3891-3902.

Jeong J, McMahon AP. 2005. Growth and pattern of the mammalian neural tube are governed by partially overlapping feedback activities of the hedgehog antagonists patched 1 and Hhip1. Development 132: 143-154.

Jessell TM. 2000. Neuronal specification in the spinal cord: Inductive signals and transcriptional codes. Nat Rev Genet 1: 20-29.

Joksimovic M, Yun BA, Kittappa R, Anderegg AM, Chang WW, Taketo MM, McKay RD, Awatramani RB. 2009. Wnt antagonism of Shh facilitates midbrain floor plate neurogenesis. Nat Neurosci 12: 125-131.

Karlstrom RO, Tyurina OV, Kawakami A, Nishioka N, Talbot WS, Sasaki H, Schier AF. 2003. Genetic analysis of zebrafish gli1 and gli2 reveals divergent requirements for gli genes in vertebrate development. Development 130: 1549-1564.

Le Douarin NM, Halpern ME. 2000. Discussion point. Origin and specification of the neural tube floor plate: Insights from the chick and zebrafish. Curr Opin Neurobiol 10: 23-30.

Lee J, Platt KA, Censullo P, Ruiz i Altaba A. 1997. Glil is a target of Sonic hedgehog that induces ventral neural tube development. Development 124: 2537-2552.

Lei Q, Zelman AK, Kuang E, Li S, Matise MP. 2004. Transduction of graded Hedgehog signaling by a combination of Gli2 and Gli3 activator functions in the developing spinal cord. Development 131: 3593-3604.

Lewis KE, Concordet JP, Ingham PW. 1999. Characterisation of a second patched gene in the zebrafish Danio rerio and the differential response of patched genes to Hedgehog signalling. Dev Biol 208: 14-29.

Marigo V, Tabin CJ. 1996. Regulation of patched by sonic hedgehog in the developing neural tube. Proc Natl Acad Sci USA 93: 9346-9351.

Marigo V, Johnson RL, Vortkamp A, Tabin CJ. 1996. Sonic hedgehog differentially regulates expression of GLI and GLI3 during limb development. Dev Biol 180: 273-283.

Martinelli DC, Fan CM. 2007. Gas1 extends the range of Hedgehog action by facilitating its signaling. Genes Dev 21: 1231-1243

Matise MP, Epstein DJ, Park HL, Platt KA, Joyner AL. 1998. Gli2 is required for induction of floor plate and adjacent cells, but not most ventral neurons in the mouse central nervous system. Development 125: 2759-2770.

Miura H, Yanazawa M, Kato K, Kitamura K. 1997. Expression of a novel aristaless related homeobox gene 'Arx' in the vertebrate telencephalon, diencephalon and floor plate. Mech Dev 65: 99-109.

Morikawa Y, Hisaoka T, Senba E. 2009. Characterization of Foxp2-expressing cells in the developing spinal cord. Neuroscience 162: 1150-1162.
Motoyama J, Milenkovic L, Iwama M, Shikata Y, Scott MP, Hui CC. 2003. Differential requirement for Gli2 and Gli3 in ventral neural cell fate specification. Dev Biol 259: 150-161.

Muller F, Albert S, Blader P, Fischer N, Hallonet M, Strahle U. 2000. Direct action of the nodal-related signal cyclops in induction of sonic hedgehog in the ventral midline of the CNS. Development 127: 3889-3897.

Norton WH, Mangoli M, Lele Z, Pogoda HM, Diamond B, Mercurio S, Russell C, Teraoka H, Stickney HL, Rauch GJ, et al. 2005. Monorail/Foxa2 regulates floorplate differentiation and specification of oligodendrocytes, serotonergic raphe neurones and cranial motoneurones. Development 132: 645-658.

Odenthal J, van Eeden FJ, Haffter P, Ingham PW, NussleinVolhard C. 2000. Two distinct cell populations in the floor plate of the zebrafish are induced by different pathways. Dev Biol 219: 350-363.

Patten I, Placzek M. 2002. Opponent activities of Shh and BMP signaling during floor plate induction in vivo. Curr Biol 12: $47-52$.

Patten I, Kulesa P, Shen MM, Fraser S, Placzek M. 2003. Distinct modes of floor plate induction in the chick embryo. Development 130: 4809-4821.

Placzek M, Briscoe J. 2005. The floor plate: Multiple cells, multiple signals. Nat Rev Neurosci 6: 230-240.

Placzek M, Yamada T, Tessier-Lavigne M, Jessell T, Dodd J. 1991. Control of dorsoventral pattern in vertebrate neural development: Induction and polarizing properties of the floor plate. Dev Suppl 2: 105-122.

Placzek M, Jessell TM, Dodd J. 1993. Induction of floor plate differentiation by contact-dependent, homeogenetic signals. Development 117: 205-218.

Placzek M, Dodd J, Jessell TM. 2000. Discussion point. The case for floor plate induction by the notochord. Curr Opin Neurobiol 10: 15-22.

Poirier K, Van Esch H, Friocourt G, Saillour Y, Bahi N, Backer S, Souil E, Castelnau-Ptakhine L, Beldjord C, Francis F, et al. 2004. Neuroanatomical distribution of ARX in brain and its localisation in GABAergic neurons. Brain Res Mol Brain Res 122: $35-46$.

Rastegar S, Albert S, Le Roux I, Fischer N, Blader P, Muller F, Strahle U. 2002. A floor plate enhancer of the zebrafish netrin1 gene requires Cyclops (Nodal) signalling and the winged helix transcription factor FoxA2. Dev Biol 252: 1-14.

Roelink H, Porter JA, Chiang C, Tanabe Y, Chang DT, Beachy PA, Jessell TM. 1995. Floor plate and motor neuron induction by different concentrations of the amino-terminal cleavage product of sonic hedgehog autoproteolysis. Cell 81: 445-455.

Ruiz i Altaba A, Jessell TM, Roelink H. 1995. Restrictions to floor plate induction by hedgehog and winged-helix genes in the neural tube of frog embryos. Mol Cell Neurosci 6: 106121.

Sampath K, Rubinstein AL, Cheng AM, Liang JO, Fekany K, Solnica-Krezel L, Korzh V, Halpern ME, Wright CV. 1998. Induction of the zebrafish ventral brain and floorplate requires cyclops/nodal signalling. Nature 395: 185-189.

Sasaki H, Hogan BL. 1994. HNF-3 $\beta$ as a regulator of floor plate development. Cell 76: 103-115.

Sasaki H, Hui C, Nakafuku M, Kondoh H. 1997. A binding site for Gli proteins is essential for HNF-3 $\beta$ floor plate enhancer activity in transgenics and can respond to Shh in vitro. Development 124: 1313-1322.

Schafer M, Kinzel D, Winkler C. 2007. Discontinuous organization and specification of the lateral floor plate in zebrafish. Dev Biol 301: 117-129. 
Schoenwolf GC, Bortier H, Vakaet L. 1989. Fate mapping the avian neural plate with quail/chick chimeras: Origin of prospective median wedge cells. J Exp Zool 249: 271-278.

Schweitzer R, Vogan KJ, Tabin CJ. 2000. Similar expression and regulation of Gli2 and Gli3 in the chick limb bud. Mech Dev 98: $171-174$

Stamataki D, Ulloa F, Tsoni SV, Mynett A, Briscoe J. 2005. A gradient of Gli activity mediates graded Sonic Hedgehog signaling in the neural tube. Genes Dev 19: 626-641.

Strahle U, Blader P, Henrique D, Ingham PW. 1993. Axial, a zebrafish gene expressed along the developing body axis, shows altered expression in cyclops mutant embryos. Genes Dev 7: 1436-1446.

Strahle U, Lam CS, Ertzer R, Rastegar S. 2004. Vertebrate floorplate specification: Variations on common themes. Trends Genet 20: 155-162.

Strigini M, Cohen SM. 1997. A Hedgehog activity gradient contributes to AP axial patterning of the Drosophila wing. Development 124: 4697-4705.

Takahashi K, Liu FC, Hirokawa K, Takahashi H. 2008. Expression of Foxp4 in the developing and adult rat forebrain. I Neurosci Res 86: 3106-3116.

Teillet MA, Lapointe F, Le Douarin NM. 1998. The relationships between notochord and floor plate in vertebrate development revisited. Proc Natl Acad Sci USA 95: 11733-11738.

Tenzen T, Allen BL, Cole F, Kang JS, Krauss RS, McMahon AP. 2006. The cell surface membrane proteins Cdo and Boc are components and targets of the Hedgehog signaling pathway and feedback network in mice. Dev Cell 10: 647-656.

Tessier-Lavigne M, Goodman CS. 1996. The molecular biology of axon guidance. Science 274: 1123-1133.

Thisse C, Thisse B, Schilling TF, Postlethwait JH. 1993. Structure of the zebrafish snaill gene and its expression in wildtype, spadetail and no tail mutant embryos. Development 119: $1203-1215$.

Tian J, Yam C, Balasundaram G, Wang H, Gore A, Sampath K. 2003. A temperature-sensitive mutation in the nodal-related gene cyclops reveals that the floor plate is induced during gastrulation in zebrafish. Development 130: 3331-3342.

Towers M, Mahood R, Yin Y, Tickle C. 2008. Integration of growth and specification in chick wing digit-patterning. Nature 452: 882-886.

Ueno S, Weidinger G, Osugi T, Kohn AD, Golob JL, Pabon L, Reinecke H, Moon RT, Murry CE. 2007. Biphasic role for $\mathrm{Wnt} / \beta$-catenin signaling in cardiac specification in zebrafish and embryonic stem cells. Proc Natl Acad Sci USA 104: 9685-9690.

van Straaten HW, Hekking JW, Beursgens JP, Terwindt-Rouwenhorst E, Drukker J. 1989. Effect of the notochord on proliferation and differentiation in the neural tube of the chick embryo. Development 107: 793-803.

Varga ZM, Amores A, Lewis KE, Yan YL, Postlethwait JH, Eisen JS, Westerfield M. 2001. Zebrafish smoothened functions in ventral neural tube specification and axon tract formation. Development 128: 3497-3509.

Varlet I, Collignon J, Robertson EJ. 1997. Nodal expression in the primitive endoderm is required for specification of the anterior axis during mouse gastrulation. Development 124: 1033-1044.

Vokes SA, Ji H, Wong WH, McMahon AP. 2008. A genome-scale analysis of the cis-regulatory circuitry underlying sonic hedgehog-mediated patterning of the mammalian limb. Genes Dev 22: 2651-2663.

Wandzioch E, Zaret KS. 2009. Dynamic signaling network for the specification of embryonic pancreas and liver progenitors. Science 324: 1707-1710.
Weinstein DC, Ruiz i Altaba A, Chen WS, Hoodless P, Prezioso VR, Jessell TM, Darnell JE Jr. 1994. The winged-helix transcription factor HNF-3 $\beta$ is required for notochord development in the mouse embryo. Cell 78: 575-588.

Yamada T, Placzek M, Tanaka H, Dodd J, Jessell TM. 1991. Control of cell pattern in the developing nervous system: Polarizing activity of the floor plate and notochord. Cell 64: 635-647.

Yamada T, Pfaff SL, Edlund T, Jessell TM. 1993. Control of cell pattern in the neural tube: Motor neuron induction by diffusible factors from notochord and floor plate. Cell 73: 673-686.

Yu X, Ng CP, Habacher H, Roy S. 2008. Foxj1 transcription factors are master regulators of the motile ciliogenic program. Nat Genet 40: 1445-1453.

Zhang XM, Ramalho-Santos M, McMahon AP. 2001. Smoothened mutants reveal redundant roles for Shh and Ihh signaling including regulation of $\mathrm{L} / \mathrm{R}$ symmetry by the mouse node. Cell 106: 781-792.

Zhu J, Nakamura E, Nguyen MT, Bao X, Akiyama H, Mackem S. 2008. Uncoupling Sonic hedgehog control of pattern and expansion of the developing limb bud. Dev Cell 14: 624-632. 


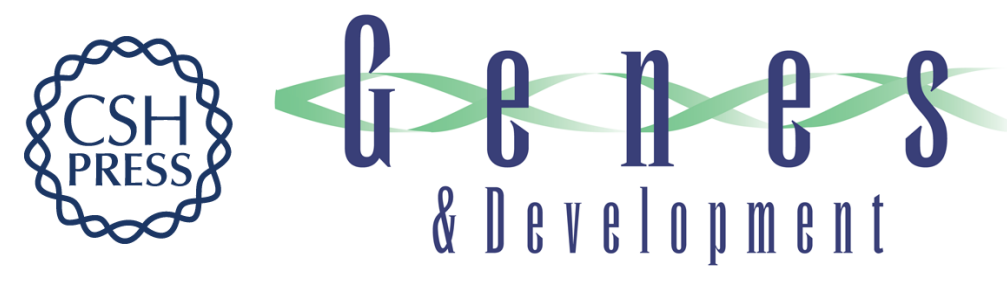

\section{Distinct Sonic Hedgehog signaling dynamics specify floor plate and ventral neuronal progenitors in the vertebrate neural tube}

Vanessa Ribes, Nikolaos Balaskas, Noriaki Sasai, et al.

Genes Dev. 2010, 24:

Access the most recent version at doi:10.1101/gad.559910

Supplemental http://genesdev.cshlp.org/content/suppl/2010/05/26/24.11.1186.DC1
Material

References This article cites 90 articles, 39 of which can be accessed free at: http://genesdev.cshlp.org/content/24/11/1186.full.html\#ref-list-1

License

Email Alerting

Receive free email alerts when new articles cite this article - sign up in the box at the top

Service

right corner of the article or click here.

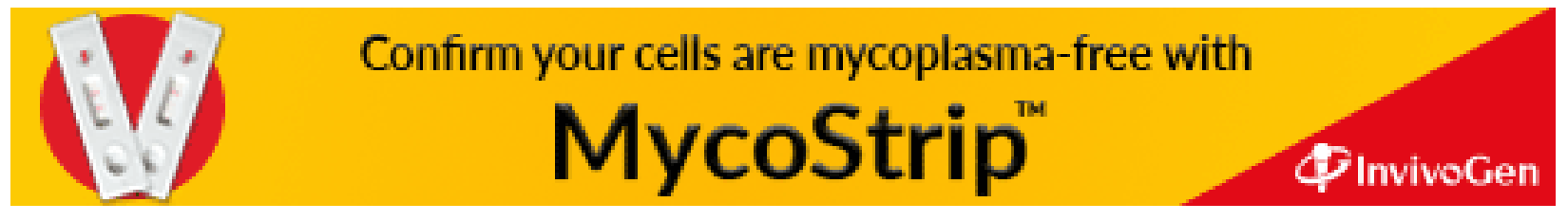

